\title{
Sectoral Price Facts in a Sticky-Price Model*
}

\author{
Carlos Carvalho \\ PUC-Rio
}

\author{
Jae Won Lee \\ Rutgers University
}

September 2011

\begin{abstract}
We develop a multi-sector sticky-price DSGE model that can endogenously deliver differential responses of prices to aggregate and sectoral shocks. Input-output production linkages induce across-sector pricing complementarities that contribute to a slow response of prices to aggregate shocks. In turn, input-market segmentation at the sectoral level induces within-sector pricing substitutability, which helps the model deliver a fast response of prices to sector-specific shocks. We estimate the model using aggregate and sectoral price and quantity data for the U.S., and find that it accounts extremely well for a range of sectoral price facts.
\end{abstract}

JEL classification codes: E30, E31, E32

Keywords: heterogeneity, price stickiness, sectoral data, FAVAR, aggregate shocks, sectoral shocks

${ }^{*}$ This paper was written while Carlos Carvalho was an economist at the Federal Reserve Bank of New York. For comments and suggestions we thank seminar participants at Stanford, UC Berkeley, San Francisco Fed, Riksbank, Norges Bank, CREI, NBER Summer Institute 2010 - EFSF, Dallas Fed, SED 2010, University of Maryland - College Park, Bank of Spain, CFS-ECB-Bundesbank joint seminar, Philadelphia Fed, AEA Annual Conference 2011, University of Rochester, 16th Australasian Macroeconomics Workshop, Reserve Bank of Australia, Economics Conference in SNU 2011, and ESEM 2011. E-mails: cvianac@econ.puc-rio.br, jwlee@economics.rutgers.edu. 


\section{Introduction}

The increasing availability of very disaggregated price data has generated a renewed flurry of activity around models of price setting. In particular, there is growing interest in taking fully-specified models that have arguably been successful in accounting for the dynamic behavior of various macroeconomic aggregates and confronting their implications for the behavior of prices at more disaggregated levels with the new empirical evidence (e.g. Klenow and Kryvtsov 2009).

This is an important area for research in macroeconomics. Assumptions about the nature of the price-setting process are key determinants of the conclusions that can be drawn from the vast majority of fully-specified macroeconomic models that have been brought to bear on actual policy questions, and are regularly used by central banks around the world as an input to the monetary policy decisionmaking process. Knowledge of how these models fare when confronted with more disaggregated price data can shed light on whether their ability to match aggregate dynamics comes at the expense of poor performance or implausible implications in other dimensions. In turn, this may provide guidance for the development of alternative models that perform well along those dimensions, and hence are arguably more reliable for policy analysis.

While most of the available empirical evidence in the literature is based on micro data on prices of individual goods and services (Bils and Klenow 2004, and many subsequent papers), a growing literature has produced novel empirical facts about the behavior of sectoral prices. In this paper we assess the ability of sticky-price models of the kind that are now routinely used for policy analysis to account for those facts.

A prominent paper in this growing literature is Boivin et al. (2009) (henceforth BGM). ${ }^{1}$ The authors employ a Factor Augmented Vector Autoregression (FAVAR) framework to analyze the response of quite disaggregated price idices to different shocks, considering the natural partition of shocks into common and series-specific that is inherent in their empirical methodology. Among their findings, one seems to be particularly challenging to standard models of price setting, and have thus caught the attention of researchers in the field: sectoral prices seem to respond faster to "idiosyncratic" (series-specific) shocks than to "aggregate" (common) shocks.

At a first pass, intuition suggests that this pattern is hard to square with most available models of price setting. Consider, for example, a (menu-cost) model in which firms optimally choose when to incur a fixed cost to change prices, and are subject to aggregate and sectoral shocks. Since paying the menu cost allows a firm to choose whichever price it desires, it should take the opportunity to respond to all relevant shocks. Alternatively, consider the Calvo (1983) model of price setting. Since firms'

\footnotetext{
${ }^{1}$ Other recent empirical papers on sectoral price dynamics are Clark (2006), Balke and Wynne (2007), Altissimo et al. (2009), Maćkowiak et al. (2009), Reis and Watson (2010), Beck et al. (2010), De Graeve and Walentin (2011), and Andrade and Zachariadis (2011).
} 
infrequent opportunities to change prices arrive exogenously, they should again take the occasion to respond to all shocks. This type of reasoning suggests that these models of price setting - and other models in which firms change prices infrequently, for that matter - should have difficulty generating price responses with different speeds to different shocks. ${ }^{2}$

To investigate whether standard sticky-price models can account for the new empirical evidence - in particular for the differential speed of price responses to different shocks - we rely on a relatively simple variant of the standard New Keynesian model. Price-setting firms are distributed across a number of sectors, and change prices infrequently as in the Calvo (1983) model. Each firm produces a differentiated variety of a good by combining a sector-specific production input with other firms' varieties. Sectors are subject to idiosyncratic demand and supply shocks, and differ in the degree of price stickiness, in accordance with the available empirical evidence. In addition, the economy is subject to aggregate demand and supply shocks. Households maximize expected discounted utility, and supply labor to price-setting firms. Finally, the specification of how monetary and fiscal policies are conducted closes the model.

In order to establish a benchmark for comparisons and build intuition, we start our analysis by finding restrictions on parameter values under which our model conforms with the "first-pass intuition" laid out previously, and delivers the exact same response of sectoral prices to aggregate and sectoral shocks. The specification that produces this result features a monetary policy that does not respond to endogenous variables, coupled with what we refer to as "strategic neutrality in price setting." Under these restrictions, nominal marginal costs become a combination of exogenous driving processes. In that case, if aggregate and sectoral shocks exhibit the same dynamics, the model delivers the same response of sectoral prices irrespective of the nature of the shock. In what follows we refer to this case as the "first-pass specification."

Departing from that specification, we find that our multi-sector sticky-price model can generate differences in the speed of price responses to aggregate and sectoral shocks endogenously. The reason is that, in general, a firm's nominal marginal cost depends also on endogenous variables - in particular, on other prices. Thus, despite the frequency of price changes being exogenous and independent of the nature of the shock, to the extent that those endogenous variables exhibit differential responses to different shocks, so do sectoral prices. ${ }^{3}$

We identify three departures from the aforementioned first-pass specification which deliver en-

\footnotetext{
${ }^{2}$ Similar points have been made elsewhere in the literature. For example, when writing about the Calvo (1983) model of price setting, Maćkowiak and Smets (2009) conjecture that "If the frequency of price changes were decisive for impulse responses, one would expect prices to respond with roughly equal speed to both kinds of shocks". Regarding menu-cost models, Maćkowiak et al. (2009) argue that "when firms respond quickly to sector-specific shocks and sector-specific shocks hit frequently, then firms also respond quickly to aggregate shocks."

${ }^{3}$ The last statement is somewhat circular - this is inherent in general equilibrium models. The reason why pricing interactions can produce differential responses to shocks will become clear subsequently.
} 
dogenous differential responses of marginal costs to aggregate and sectoral shocks in our model. The first departure is the input-output production structure, borrowed from Basu (1995). Firms use other goods as production inputs, and this creates a direct dependence of their marginal costs on the aggregate price level. In this context, whenever a shock affects the aggregate price level, such complementarity interacts with the staggering of price changes to produce a sluggish response of prices in particular, of sectoral prices - to that shock. This is what happens when the economy is hit with an aggregate shock. In contrast, a sectoral shock has only a small effect on the aggregate price level - thus rendering that pricing complementarity unimportant. As a result, nominal marginal costs are driven essentially by the exogenous shock, as in the first-pass specification discussed above.

The second departure is due to our assumption that the markets for a second factor of production are sector-specific. This segmentation creates a direct dependence of a firm's marginal cost on its sectoral relative price, because of an "expenditure switching effect." A higher sectoral relative price implies less demand for the sector's output, which translates into lower demand for the sector-specific input, reducing its price and thus lowering marginal costs. This positive dependence of a firm's marginal cost on the aggregate price level, and negative dependence on its own sectoral price level, produces what we refer to as a "non-uniform pricing interdependence": a strategic complementarity in price setting across sectors, and a strategic substitutability within sectors. The strategic complementarity across sectors contributes to a differential response of sectoral prices to aggregate and sectoral shocks for the same reason as the input-output production structure. In turn, because a sectoral shock does affect prices in the sector, the within-sector strategic substitutability works to speed up their response to that shock. This pattern of non-uniform pricing interactions is impossible to replicate with a version of the model that features an economy-wide market for the second production input, and requires an arguably unrealistic parameterization of the model in the case in which that second input is attached to firms, as opposed to sectors. In order to allow for an easy comparison between our model and the most commonly used sticky-price models, we introduce this second ingredient by assuming that labor is the sector-specific input.

The third departure from the first-pass specification is the (standard) assumption that monetary policy responds to endogenous variables - in particular, it takes the form of an interest-rate rule. This departure turns the nominal wage from an exogenous variable (under the first-pass specification) into an endogenous one. It induces a differential response of prices to aggregate and sectoral shocks for reasons similar to the ones spelled out previously. A sectoral shock has little effect on aggregate variables, and thus assuming that monetary policy responds to these variables makes little difference relative to the first-pass specification. In contrast, endogenous monetary policy leads aggregate shocks to have an impact on the (now endogenous) nominal wage, thus differentiating the price response relative to the first-pass specification. 
We then move to a quantitative assessment of our model. To that end we apply a Bayesian approach to estimate the model using aggregate and sectoral price and quantity data for the U.S. economy. We present results based on the impulse responses implied by the estimated model, and also by estimating a FAVAR similar to BGM's on model-generated data. We find that the model has the ability to match the differential speed of responses of sectoral prices to aggregate and sectoral shocks, as well as additional sectoral price facts.

Because of the "ingredients" that we use in the model, our paper is related to different lines of research. These include papers that follow Basu (1995) in explicitly modeling input-output production structures as a source of real rigidity, and the growing literature that incorporates heterogeneity in price setting behavior in dynamic macroeconomic models. ${ }^{4}$ In addition, our assumption of labor market segmentation relates our work to the sticky-price literature that relies on input specificity as a source of real rigidity (e.g., Woodford 2003, and Gertler and Leahy 2008). However, for reasons that we discuss in detail subsequently, the implications of input-market segmentation in our model are quite different from the results available in this literature. ${ }^{5}$ Finally, our use of sectoral data in the estimation of the structural model connects our paper with Lee (2007) and Bouakez et al. (2009).

Turning to the questions that we address in the paper, Maćkowiak et al. (2009) provide a first assessment of the ability of models with Calvo (1983) pricing to match the sectoral price facts that they document with their statistical model - in particular the "random-walk-type" response of sectoral price to series-specific shocks. They conclude that such models require extreme assumptions to match the latter fact - more specifically, assumptions that produce implausible dynamics for firms' frictionless optimal prices.

In contrast to Maćkowiak et al. (2009), we focus on the ability of our model to match a series of sectoral price facts derived from BGM's FAVAR (and variations thereofe that we estimate). These facts differ in some dimensions from the empirical findings of Maćkowiak et al. (2009). Because of our focus, we discuss in detail the mechanisms that allow our model to match BGM's sectoral price facts without the need for extreme assumptions.

Shamloo (2010) is closest to our paper. She studies a sticky-price DSGE model with a heterogeneous input-output structure, heterogeneity in price rigidity, and a monetary policy that follows a Taylor rule. She emphasizes a novel implication of her model: heterogeneous responses of prices to aggregate shocks that are due to differences across sectors in the importance of intermediate goods as production inputs - which she relates empirically to the location of the sectors along the "production chain." In contrast, she also points out that all sectoral prices respond to their own sectoral shocks

\footnotetext{
${ }^{4}$ For brevity we refer the reader to Carvalho and Schwartzman (2008) for a review of this literature.

${ }^{5}$ Our assumption regarding the labor market is the same as in, e.g., Carlstrom et al. (2006). However, to our knowledge the existing papers that assume labor market segmentation at the sectoral level do not explore its implications for the pattern of interdependence among firms' pricing decisions.
} 
quickly in her model.

While the pattern of price responses produced by Shamloo's model is consistent with the findings of Maćkowiak et al. (2009) - who emphasize that the distribution of the speed of price responses to sectoral shocks is tighter than the distribution of the speed of responses to aggregate shocks - it is in fact opposite to what we find using BGM's FAVAR framework. We show that in BGM's FAVAR and in alternative specifications that we estimate - the tighter distribution of the speed of responses of sectoral prices is the one obtained in response to common shocks. Our estimated structural model matches the finding that we document with BGM's FAVAR, rather than the opposite finding of Maćkowiak et al. (2009). ${ }^{6}$

Finally, our approach of analyzing both the data and the results of our estimated model through the lens of a FAVAR produces a tangential contribution to the FAVAR literature. On one side, it provides evidence that such statistical models can reasonably recover some properties of structural models. On the other side, this approach uncovers differences between model-implied and FAVARbased impulse response functions that remind us of the pitfalls involved in assessing the ability of structural models to match empirical facts derived from reduced-form statistical models.

\section{The model}

The model is a variant of the standard New Keynesian model, from which we make the following departures: i) add multiple sectors that are subject to idiosyncratic demand and supply shocks, and that differ in the degree of price stickiness; ii) assume that firms' varieties are also used as intermediate inputs in production; and iii) assume that labor markets are sector-specific. We follow Woodford (2003) in working with the cashless limit of a monetary economy.

The economy is divided into a finite number of sectors indexed by $k \in\{1,2, \ldots, K\}$. There is a continuum of firms indexed by $i \in[0,1]$ and each firm belongs to one of the $K$ sectors and produces a differentiated good that is used for consumption and as an intermediate input. We refer to firm $i$ that belongs to sector $k$ as "firm $i k$." We use $\mathcal{I}_{k}$ to denote the set that contains the indices of firms

that belong to sector $k$ (so that $\bigcup_{k=1}^{K} \mathcal{I}_{k}=[0,1]$ ). Its measure, denoted $n_{k}$, gives the size of (mass of firms belonging to) the sector.

\subsection{Representative Household}

The representative consumer derives utility from a composite consumption good, supplies different types of labor to firms in different sectors, and has access to a complete set of state-contingent claims.

\footnotetext{
${ }^{6}$ This implication of our estimated structural model is not "hard-wired" into it. Under a suitable parameterization it is also capable of producing the opposite result regarding the cross-sectional dispersion of the speeds of price responses to aggregate and sectoral shocks.
} 
Subject to the budget constraint presented below, she maximizes

$$
E_{0}\left[\sum_{t=0}^{\infty} \beta^{t} \Gamma_{t}\left(\log \left(C_{t}\right)-\sum_{k=1}^{K} \omega_{k} \frac{H_{k, t}^{1+\varphi}}{1+\varphi}\right)\right]
$$

where $C_{t}$ denotes the household's consumption of the composite good, and $H_{k, t}$ denotes the hours of labor services supplied to sector $k$. Labor is fully mobile within each sector, but immobile across sectors. The parameters $\beta, \varphi$, and $\left\{\omega_{k}\right\}_{k=1}^{K}$ are, respectively, the discount factor, the inverse of the (Frisch) elasticity of labor supply, and the relative disutilities of supplying hours to sector $k . \Gamma_{t}$ denotes the aggregate preference shock.

The flow budget constraint of the household is given by

$$
P_{t} C_{t}+E_{t}\left[Q_{t, t+1} B_{t+1}\right]=B_{t}+\sum_{k=1}^{K} W_{k, t} H_{k, t}+\sum_{k=1}^{K} \int_{\mathcal{I}_{k}} \Pi_{k, t}(i) d i
$$

where $P_{t}$ denotes the aggregate price level to be defined below, $W_{k, t}$ is the wage rate in sector $k$, and $\Pi_{k, t}(i)$ denotes profits of firm $i k$. Households can trade nominal securities with arbitrary patterns of state-contingent payoffs. $B_{t+1}$ denotes household's holding of one-period state-contingent nominal securities and $Q_{t, t+1}$ is the nominal stochastic discount factor.

The aggregate consumption composite is:

$$
C_{t}=\left(\sum_{k=1}^{K}\left(n_{k} D_{k, t}\right)^{1 / \eta} C_{k, t}(\eta-1) / \eta\right)^{\eta /(\eta-1)}
$$

where $\eta$ is the elasticity of substitution between the sectoral consumption composites to be defined below, and $D_{k, t}>0$ is a relative demand shock satisfying $\sum_{k=1}^{K} n_{k} D_{k, t}=1$. The underlying aggregate price index is

$$
P_{t}=\left(\sum_{k=1}^{K}\left(n_{k} D_{k, t}\right) P_{k, t}^{1-\eta}\right)^{1 /(1-\eta)},
$$

where $P_{k, t}$ is the sectoral price index associated with the sectoral consumption composite $C_{k, t}$. Given aggregate consumption $C_{t}$, and the price levels $P_{k, t}$ and $P_{t}$, the optimal demand for the sectoral composite goods, which minimizes total expenditure $P_{t} C_{t}$, is given by

$$
C_{k, t}=n_{k} D_{k, t}\left(\frac{P_{k, t}}{P_{t}}\right)^{-\eta} C_{t}
$$

Sectoral consumption composites are given by

$$
C_{k, t}=\left(\left(\frac{1}{n_{k}}\right)^{1 / \theta} \int_{\mathcal{I}_{k}} C_{k, t}(i)^{(\theta-1) / \theta} d i\right)^{\theta /(\theta-1)}
$$


with corresponding sectoral price indices

$$
P_{k, t}=\left(\frac{1}{n_{k}} \int_{\mathcal{I}_{k}} P_{k, t}(i)^{1-\theta} d i\right)^{1 /(1-\theta)},
$$

where $\theta$ denotes the within-sector elasticity of substitution between consumption varieties. Given $C_{k, t}$, the optimal demand for firm $i k$ 's good, $C_{k, t}(i)$, is:

$$
C_{k, t}(i)=\frac{1}{n_{k}}\left(\frac{P_{k, t}(i)}{P_{k, t}}\right)^{-\theta} C_{k, t}
$$

The two remaining first-order conditions for the household's problem are:

$$
\begin{aligned}
& Q_{t, t+1}=\beta\left(\frac{\Gamma_{t}}{\Gamma_{t+1}}\right)\left(\frac{C_{t}}{C_{t+1}}\right)\left(\frac{P_{t}}{P_{t+1}}\right), \\
& \frac{W_{k, t}}{P_{t}}=\omega_{k} H_{k, t}^{\varphi} C_{t} .
\end{aligned}
$$

\section{$2.2 \quad$ Firms}

Firms use sector-specific labor and other (intermediate) goods to produce according to the following technology:

$$
Y_{k, t}(i)=A_{t} A_{k, t} H_{k, t}(i)^{1-\delta} Z_{k, t}(i)^{\delta}
$$

where $Y_{k, t}(i)$ is the production of firm $i k, A_{t}$ is economy-wide productivity, $A_{k, t}$ is sector-specific productivity, $H_{k, t}(i)$ denotes hours of labor that firm $i k$ employs, $Z_{k, t}(i)$ is firm $i k$ 's usage of other goods as intermediate inputs, and $\delta$ is the elasticity of output with respect to intermediate inputs.

Firms combine the varieties of goods to form composites of sectoral intermediate inputs through a Dixit-Stiglitz aggregator. The sectoral intermediate inputs are further assembled into the composite intermediate input that can be used for production. The total quantity of intermediate inputs employed by firm $i k$ is a Dixit-Stiglitz aggregator of sectoral intermediate inputs with the same across-sector elasticity of substitution as the one between consumption varieties:

$$
Z_{k, t}(i)=\left(\sum_{k^{\prime}=1}^{K}\left(n_{k^{\prime}} D_{k^{\prime}, t}\right)^{1 / \eta} Z_{k, k^{\prime}, t}(i)^{(\eta-1) / \eta}\right)^{\eta /(\eta-1)}
$$

where the sectoral intermediate input, $Z_{k, k^{\prime}, t}(i)$, denotes the amount of firm $i k$ 's usage of sector- $k^{\prime}$ goods as intermediate inputs, and is given by

$$
Z_{k, k^{\prime}, t}(i)=\left(\left(\frac{1}{n_{k^{\prime}}}\right)^{1 / \theta} \int_{\mathcal{I}_{k^{\prime}}} Z_{k, k^{\prime}, t}\left(i, i^{\prime}\right)^{(\theta-1) / \theta} d i^{\prime}\right)^{\theta /(\theta-1)}
$$


$Z_{k, k^{\prime}, t}\left(i, i^{\prime}\right)$ denotes the quantity of goods that firm $i k$ purchases from firm $i^{\prime} k^{\prime}$.

Taking the prices $P_{t}, P_{k^{\prime}, t}, P_{k^{\prime}, t}(i)$, and $W_{k, t}$ as given, firm $i k$ decides how much of each input to employ in production. The cost-minimization problem yields the following optimality conditions:

$$
\begin{gathered}
Z_{k, t}(i)=\frac{\delta}{1-\delta} \frac{W_{k, t}}{P_{t}} H_{k, t}(i), \\
Z_{k, k^{\prime}, t}(i)=n_{k^{\prime}} D_{k^{\prime}, t}\left(\frac{P_{k^{\prime}, t}}{P_{t}}\right)^{-\eta} Z_{k, t}(i), \\
Z_{k, k^{\prime}, t}\left(i, i^{\prime}\right)=\frac{1}{n_{k^{\prime}}}\left(\frac{P_{k^{\prime}, t}\left(i^{\prime}\right)}{P_{k^{\prime}, t}}\right)^{-\theta} Z_{k, k^{\prime}, t}(i) .
\end{gathered}
$$

Prices are sticky as in Calvo (1983). A firm in sector $k$ adjusts its price with probability $1-\alpha_{k}$ each period. Thus, the sectoral price level $P_{k, t}$ evolves according to

$$
\begin{aligned}
P_{k, t} & =\left[\frac{1}{n_{k}} \int_{\mathcal{I}_{k, t}^{*}} P_{k, t}^{*}{ }^{1-\theta} d i+\frac{1}{n_{k}} \int_{\mathcal{I}_{k}-\mathcal{I}_{k, t}^{*}} P_{k, t-1}(i)^{1-\theta} d i\right]^{\frac{1}{1-\theta}} \\
& =\left[\left(1-\alpha_{k}\right) P_{k, t}^{*}{ }^{1-\theta}+\alpha_{k} P_{k, t-1}^{1-\theta}\right]^{\frac{1}{1-\theta}}
\end{aligned}
$$

where $P_{k, t}^{*}$ is the common price chosen by the firms that adjust at time $t$. These firms are grouped into the set $\mathcal{I}_{k, t}^{*} \subset \mathcal{I}_{k}$, which is a randomly chosen subset with measure $n_{k}\left(1-\alpha_{k}\right)$.

Firms that adjust their prices at time $t$ maximize expected discounted profits:

$$
\max _{P_{k, t}(i)} E_{t} \sum_{s=0}^{\infty} \alpha_{k}^{s} Q_{t, t+s} \Pi_{k, t+s}(i)
$$

where $Q_{t, t+s}$ and $\Pi_{k, t+s}(i)$ are respectively the stochastic discount factor between time $t$ and $t+s$ and firm $i k$ 's nominal profit at time $t+s$ given that the price chosen at time $t$ is still being charged:

$$
\begin{aligned}
Q_{t, t+s} & =\beta^{s}\left(\frac{\Gamma_{t}}{\Gamma_{t+s}}\right)\left(\frac{C_{t}}{C_{t+s}}\right)\left(\frac{P_{t}}{P_{t+s}}\right) \\
\Pi_{k, t+s}(i) & =P_{k, t}(i) Y_{k, t+s}(i)-W_{k, t+s} H_{k, t+s}(i)-P_{t+s} Z_{k, t+s}(i) .
\end{aligned}
$$

The first-order condition that determines price setting is:

$$
E_{t} \sum_{s=0}^{\infty} \alpha_{k}^{s} Q_{t, t+s}\left(\frac{P_{k, t}^{*}}{P_{k, t+s}}\right)^{-\theta}\left(\frac{P_{k, t+s}}{P_{t+s}}\right)^{-\eta} Y_{t+s}\left[P_{k, t}^{*}-\left(\frac{\theta}{\theta-1}\right) M C_{k, t+s}\right]=0
$$

where $M C_{k, t+s}=P_{t+s} A_{t+s}^{-1} A_{k, t+s}^{-1} \frac{1}{1-\delta}\left(\frac{\delta}{1-\delta}\right)^{-\delta}\left(\frac{W_{k, t+s}}{P_{t+s}}\right)^{1-\delta}$ is the nominal marginal cost of firm $i k$ at time $t+s$. Together with (2), optimal price setting determines equilibrium dynamics of sectoral prices. The aggregate price dynamics are then determined by aggregation of such sectoral prices. 


\subsection{Policy}

For simplicity we abstract from any influence of fiscal policy on equilibrium. We assume that the government does not collect taxes or purchase goods. To close the model, we consider two assumptions for monetary policy: i) that it is explicitly characterized by a Taylor-type interest-rate rule; or ii) that policy is such that nominal aggregate consumption follows a given exogenous stochastic process.

Under the explicit interest-rate rule the gross nominal interest rate $I_{t}$ is set according to

$$
I_{t}=\beta^{-1}\left(\frac{P_{t}}{P_{t-1}}\right)^{\phi_{\pi}}\left(\frac{C_{t}}{C}\right)^{\phi_{y}} \exp \left(\mu_{t}\right)
$$

where $\mu_{t}$ is a monetary policy shock, and $C$ is the zero-inflation-steady-state level of consumption.

Under the alternative assumption for monetary policy, we impose an exogenous stochastic process for nominal aggregate consumption, denoted by $M_{t} \equiv P_{t} C_{t}$. As usual, this can be rationalized by introducing an exogenous money supply and a cash-in-advance constraint on consumption.

\subsection{Equilibrium}

Equilibrium is characterized by an allocation of quantities and prices that satisfy the households' optimality conditions and budget constraint, the firms' optimality conditions, the monetary policy rule, and finally the market-clearing conditions:

$$
\begin{aligned}
B_{t} & =0 \\
H_{k, t} & =\int_{\mathcal{I}_{k}} H_{k, t}(i) d i \quad \forall k, \\
Y_{k, t}(i) & =C_{k, t}(i)+\sum_{k^{\prime}=1}^{K} \int_{\mathcal{I}_{k^{\prime}}} Z_{k^{\prime}, k, t}\left(i^{\prime}, i\right) d i^{\prime} \quad \forall i, k .
\end{aligned}
$$

The first equation is the asset market clearing condition. ${ }^{7}$ The second is the labor market clearing condition for each sector. The last condition equates supply and demand for each good, and indicates that firm $i k^{\prime} s$ output can be either consumed by the household, $C_{k, t}(i)$, or employed as inputs by other firms, $\sum_{k^{\prime}=1}^{K} \int_{\mathcal{I}_{k^{\prime}}} Z_{k^{\prime}, k, t}\left(i^{\prime}, i\right) d i^{\prime}$.

For later use, we define aggregate wage and hours indices as follows:

$$
\begin{aligned}
W_{t} & \equiv \sum_{k} n_{k} W_{k, t} \\
H_{t} & \equiv \sum_{k} H_{k, t} .
\end{aligned}
$$

\footnotetext{
${ }^{7}$ For a discussion of alternative ways to think about bond-market clearing and interest-rate determination in a cashless-limit economy see Woodford (2003).
} 


\subsection{Log-linear approximate model}

We solve the model by log-linearizing the equilibrium conditions around the deterministic zeroinflation steady state. The Appendix provides a detailed derivation of the steady-state equilibrium as well as the full set of log-linearized equations. Here we only present the equations necessary to characterize the equilibrium of the variables of interest:

$$
\left\{c_{t}, \pi_{t}, i_{t}, m_{t}, h_{t},\left(w_{t}-p_{t}\right)\right\} \text { and }\left\{c_{k, t}, \pi_{k, t}\right\}_{k=1}^{K}
$$

where lowercase letters denote log-deviation from their steady state counterparts, and $\pi_{t} \equiv p_{t}-p_{t-1}$ denotes inflation. The following $6+(2 \times K)$ equations determine the equilibrium dynamics of those variables:

$$
\begin{aligned}
& c_{t}=E_{t}\left[c_{t+1}\right]-\left(i_{t}-E_{t} \pi_{t+1}\right)+\left(\gamma_{t}-E_{t} \gamma_{t+1}\right), \\
& w_{t}-p_{t}=\varphi h_{t}+c_{t}, \\
& (1-\psi) c_{t}+\psi z_{t}=a_{t}+\sum_{k} n_{k} a_{k, t}+(1-\delta) h_{t}+\delta z_{t}, \\
& w_{t}-p_{t}=z_{t}-h_{t}, \\
& \pi_{k, t}=\beta E_{t} \pi_{k, t+1}+\frac{1-\alpha_{k}}{\alpha_{k}\left(1-\alpha_{k} \beta\right)^{-1}}\left[\begin{array}{c}
\left(\frac{(1-\delta) \varphi}{1+\delta \varphi}+\frac{1}{\eta}\right) c_{k, t}+\left(\frac{(1-\delta)(1-\psi \varphi)}{1+\delta \varphi}-\frac{1}{\eta}\right) c_{t}+\frac{(1-\delta) \psi \varphi}{1+\delta \varphi} z_{t} \\
-\frac{1+\varphi}{1+\delta \varphi} a_{t}-\frac{1+\varphi}{1+\delta \varphi} a_{k, t}-\frac{1}{\eta} d_{k, t}
\end{array}\right] \\
& \pi_{t}=\sum_{k} n_{k} \pi_{k, t} \\
& \Delta\left(c_{k, t+1}-c_{t+1}\right)=-\eta\left(\pi_{k, t+1}-\pi_{t+1}\right)+\Delta d_{k, t+1}, \\
& i_{t}=\phi_{\pi} \pi_{t}+\phi_{c} c_{t}+\mu_{t} \\
& \text { or } \\
& m_{t}=p_{t}+c_{t}=\text { exogenous stochastic process, }
\end{aligned}
$$

where $\psi=\delta(\theta-1) / \theta$. The first equation (3) is the household's consumption Euler equation, often referred to as the intertemporal IS equation; (4) is obtained by aggregating the household's intratemporal optimality conditions over sectors, and can be interpreted as an aggregate labor supply schedule; (5) is obtained by integrating the production functions over all firms; (6) results from the aggregation of cost minimization conditions; (7) gives the sectoral Phillips curves and (8) delivers aggregate inflation; the demand function for sectoral consumption goods is given by (9); the last equation, (10), closes the model. 


\section{Inspecting the mechanisms}

In this section we analyze the mechanisms through which our model can deliver a differential response of prices to sectoral and aggregate shocks. In the loglinear-approximate version of the model, when a firm sets a new price it chooses (a markup over) an expected discounted weighted average of future nominal marginal costs. Given that the frequency of price changes is the same for all types of shocks, any differential speed in the response of sectoral prices to different shocks can be traced back to differences in the dynamics of nominal marginal costs in response to these shocks.

It turns out that there are three sources of endogenous responses of marginal costs to shocks: i) pricing interactions produced by intermediate inputs; ii) pricing interactions produced by labor market segmentation; and iii) monetary policy responses to endogenous variables.

We start our discussion from a special case in which the first-pass intuition that the Calvo model should not be able to produce price responses with different speeds depending on the shock indeed holds true. We then depart from this case to highlight the three sources of endogenous differential responses one-by-one, and thus illustrate why the first-pass intuition does not hold more generally.

In our analysis, it will be useful to focus on the equations for the sectoral price levels that obtain from the sectoral Phillips curves (and some additional algebra):

$$
p_{k, t}=\lambda_{1} p_{k, t-1}+\frac{1-\alpha_{k}}{\alpha_{k}\left(1-\alpha_{k} \beta\right)^{-1}} \frac{1}{\lambda_{2}} \sum_{s=0}^{\infty}\left(\frac{1}{\lambda_{2}}\right)^{s} E_{t}\left[\begin{array}{c}
\frac{(1-\delta)\left(1-\delta \frac{\theta-1}{\theta} \varphi+\varphi\right)}{1+\delta \varphi} c_{t+s}+\frac{(1-\delta) \delta \frac{\theta-1}{\theta} \varphi}{1+\delta \varphi} z_{t+s} \\
+\left(1+\frac{1-\delta}{1+\delta \varphi} \varphi \eta\right) p_{t+s} \\
+\frac{1-\delta}{1+\delta \varphi} \varphi d_{k, t+s}-\frac{1+\varphi}{1+\delta \varphi}\left(a_{k, t+s}+a_{t+s}\right)
\end{array}\right]
$$

where $\lambda_{1}$ and $\lambda_{2}$ are the roots of the characteristic polynomial

$$
f(\lambda)=\beta \lambda^{2}-\left(\beta+1+\frac{1-\alpha_{k}}{\alpha_{k}\left(1-\alpha_{k} \beta\right)^{-1}}\left(1+\frac{1-\delta}{1+\delta \varphi} \varphi \eta\right)\right) \lambda+1
$$

and satisfy $0<\lambda_{1}<1<\lambda_{2}$. Equation (11) indicates how sectoral price levels evolve, through partialadjustment $\left(\lambda_{1} p_{k, t-1}\right)$, toward a weighted average of current and expected future values of exogenous and endogenous variables.

\subsection{Identical responses}

To get the model to produce the same response of sectoral prices to aggregate and sectoral shocks we start by abstracting from intermediate inputs $(\delta=0)$. In addition, we assume linear disutility of labor $(\varphi=0)$. This eliminates the effects of labor market segmentation, equalizing wages across sectors. Under these assumptions the model exhibits what we refer to as "strategic neutrality" - as opposed to strategic complementarity or substitutability - in price setting, and the sectoral price equations 
(11) simplify to:

$$
p_{k, t}=\lambda_{1} p_{k, t-1}+\frac{1-\alpha_{k}}{\alpha_{k}\left(1-\alpha_{k} \beta\right)^{-1}} \frac{1}{\lambda_{2}} \sum_{s=0}^{\infty}\left(\frac{1}{\lambda_{2}}\right)^{s} E_{t}\left[m_{t+s}-a_{t+s}-a_{k, t+s}\right] .
$$

Under the additional assumption that nominal consumption evolves exogenously, it is clear that the speed of the response of sectoral prices to the various shocks will be the same if the shocks have the same dynamics. ${ }^{8}$ This result follows from the fact that, under these restrictions, nominal marginal costs equal a linear combination of exogenous stochastic processes $\left(m_{t}-a_{t}-a_{k, t}\right)$.

\subsection{Differential responses}

From the result in the last subsection, it follows trivially that one source of differential dynamics in the response of sectoral prices to shocks are differences in the dynamics of the shocks themselves. To isolate this factor from the mechanisms that endogenously deliver a differential price response to shocks, in the remainder of this section we assume that all exogenous stochastic processes exhibit the same dynamics. We relax this assumption when we move to our quantitative analysis.

Departing from the particular parameterization of the previous subsection, in general the infinite sum in (11) will involve current and expected future values of endogenous variables. This follows directly from the fact that, in general, nominal marginal costs depend on endogenous variables. Thus, any difference in the speed of response to two given shocks will depend on how these shocks affect the relevant endogenous variables.

\subsubsection{The effect of intermediate inputs $\left(\delta>0, \varphi=0, m_{t}\right.$ exogenous $)$}

We continue to neutralize the effect of labor market segmentation by setting $\varphi=0$, and maintain the assumption of exogenous nominal consumption. This leads to the following sectoral price equations:

$$
p_{k, t}=\lambda_{1} p_{k, t-1}+\frac{1-\alpha_{k}}{\alpha_{k}\left(1-\alpha_{k} \beta\right)^{-1}} \frac{1}{\lambda_{2}} \sum_{s=0}^{\infty}\left(\frac{1}{\lambda_{2}}\right)^{s} E_{t}\left[\begin{array}{c}
(1-\delta) m_{t+s}-\left(a_{k, t+s}+a_{t+s}\right) \\
+\delta p_{t+s}
\end{array}\right]
$$

In the expression between square brackets, the first line only involves exogenous processes, and can be thought of as giving the direct effect of the shocks on sectoral prices. The second line, however, involves the aggregate price level. To the extent that the latter responds differently to aggregate and sectoral shocks, the same will happen to sectoral prices. Note that this involves a circular argument, since the aggregate price level is simply a combination of sectoral prices. Thus, understanding the mechanism through which the model delivers a differential response of prices to shocks amounts to understanding the dynamics of prices in general equilibrium.

\footnotetext{
${ }^{8}$ Note that in this case demand shocks have no effect on sectoral prices. This arises because wage equalization implies that pure relative-demand shifts have no effect on marginal costs.
} 
Relative to aggregate shocks, sectoral (productivity) shocks have only a small effect on the aggregate price level - which for expositional purposes we take to be zero. ${ }^{9}$ Thus the speed of the response of sectoral prices to the latter shocks is mechanically dictated by the dynamics of the shocks themselves, since they determine the evolution of nominal marginal costs - just as in the case of identical responses analyzed in the previousd subsection.

In contrast, an aggregate shock does move the aggregate price level, and thus the speed of its response matters. As is well known, intermediate inputs lead to strategic complementarity in pricing decisions: when adjusting their prices, firms do not adjust as much in response to shocks since nominal marginal costs are "held back" by prices that have not yet adjusted. This interdependence of pricing decisions manifests itself through the terms $E_{t}\left[\delta p_{t+s}\right]$ in equation (13). This mechanism implies a slower response of prices to aggregate shocks when compared to the case of identical responses analyzed previously - and thus a slower response relative to sectoral shocks.

\subsubsection{The effect of labor market segmentation $\left(\delta=0, \varphi>0, m_{t}\right.$ exogenous $)$}

We continue to assume exogenous nominal consumption (output), but now abstract from intermediate inputs $(\delta=0)$. This leads to the following sectoral price equations:

$$
p_{k, t}=\lambda_{1} p_{k, t-1}+\frac{1-\alpha_{k}}{\alpha_{k}\left(1-\alpha_{k} \beta\right)^{-1}} \frac{1}{\lambda_{2}} \sum_{s=0}^{\infty}\left(\frac{1}{\lambda_{2}}\right)^{s} E_{t}\left[\begin{array}{c}
(1+\varphi) m_{t+s}-(1+\varphi) a_{t+s} \\
-(1+\varphi) a_{k, t+s}+\varphi d_{k, t+s} \\
+\varphi(\eta-1) p_{t+s}
\end{array}\right] .
$$

In the expression between square brackets, the first two lines only involve exogenous processes. The third line, however, involves the aggregate price level, and, just like in the previous subsection, the speed of its response matters in the case of aggregate shocks.

Equation (14) is consistent with sectoral prices displaying a slower or faster response to aggregate shocks relative to sectoral shocks, depending on whether the coefficient in front of the aggregate price level is, respectively, positive or negative. As we discuss in detail in Subsection 3.3, the sign of this coefficient depends on whether pricing decisions of firms in any given sector are strategic complements or substitutes relative to pricing decisions elsewhere in the economy. Pricing decisions exhibit this type of complementarity (substitutability) when the coefficient $\varphi(\eta-1)$ is positive (negative). ${ }^{10}$

In the $\varphi(\eta-1)$ coefficient on the aggregate price level, the $-\varphi$ term is reminiscent of models with an economy-wide labor market, and pushes toward across-sector strategic substitutability in

\footnotetext{
${ }^{9}$ Recall that this is a statement about the effect of identical shocks.

${ }^{10}$ From this coefficient it may appear that in general $\eta=1$ is a borderline case between complementarity and substitutability. However, this is only the case because we assumed logarithmic consumption utility. In the case of general CRRA preferences with coefficient of intertemporal substitution in consumption $\sigma^{-1}$, the condition for strategic neutrality in price setting is $1+\varphi \eta-(\sigma+\varphi)=0$.
} 
price setting. ${ }^{11}$ The $\varphi \eta$ term, which arises precisely because of the sectoral labor market assumption, unequivocally pushes toward across-sector strategic complementarity in price setting. This effect is stronger the lower the (Frisch) elasticity of labor supply is (higher $\varphi$ ) and the higher the elasticity of substitution across sectors, $\eta$, is. In Subsection 3.3 we discuss the intuition behind the roles of these two parameters.

\subsubsection{Taylor rule}

In addition to the mechanisms discussed in the previous two subsections, a response of monetary policy to endogenous variables - according to a Taylor-type interest rate rule - may also produce differential responses of sectoral prices to shocks. A convenient way to think about this case is to factor in that nominal consumption $\left(m_{t} \equiv p_{t}+c_{t}\right)$ becomes endogenous. Thus, even in the simplifying case of strategic neutrality in price setting $(\delta=0, \varphi=0)$, aggregate shocks should lead prices to respond differently from sectoral shocks, since the former should affect $p_{t}$ and $c_{t}$.

\subsection{The nature of pricing interactions}

The previous analysis highlights pricing interactions as a feature that gives the model the ability to deliver relatively more sluggish responses of sectoral prices to aggregate shocks vis-a-vis sectoral shocks endogenously. In our model, these interactions may arise due to input-output linkages, and sectoral labor markets.

Input-output linkages produce complementarities "uniformly" across all pricing decisions, in the sense that other prices only matter as an average - in particular, the aggregate price level. To see this, assume linear labor disutility $(\varphi=0)$ to shut down the effect of labor market segmentation. This produces the following expression for firm $i k$ 's frictionless optimal price $p_{k, t}^{* *}(i):^{12}$

$$
\begin{aligned}
p_{k, t}^{* *}(i) & =p_{t}+(1-\delta) c_{t}-a_{t}-a_{k, t} \\
& =(1-\delta) m_{t}+\delta p_{t}-a_{t}-a_{k, t}
\end{aligned}
$$

Note that the aggregate price level appears multiplied by the the elasticity of output with respect to intermediate inputs - which in this case dictates the strength of the pricing complementarities. This mechanism operates in the same way in models with economy-wide labor markets (as in the RBC tradition) or firm-specific labor (as advocated by Woodford 2003). It follows directly from the fact that goods are inputs to production, and thus their prices affect marginal costs.

In contrast, labor market segmentation at the sectoral level produces a different type of pricing

\footnotetext{
${ }^{11}$ In the general case of CRRA preferences with coefficient of intertemporal substitution in consumption $\sigma^{-1}$, the corresponding term would be $1-(\sigma+\varphi)$.

${ }^{12}$ This is the price that firm $i k$ would choose if it could change prices continuously.
} 
interactions. To see this, abstract from intermediate inputs $(\delta=0)$ and make labor segmentation relevant by assuming $\varphi>0$. This produces the following expression for firm $i k$ 's frictionless optimal price:

$$
\begin{aligned}
p_{k, t}^{* *}(i)= & (1+\varphi) m_{t}-\varphi p_{t}+\varphi \eta p_{t}-\varphi \eta p_{k, t} \\
& +\varphi d_{k, t}-(1+\varphi)\left(a_{t}+a_{k, t}\right) .
\end{aligned}
$$

The first two terms on the right-hand-side of (15) are reminiscent of models with an economy-wide labor market. They imply a strategic substitutability in price setting. Sectoral labor market segmentation creates a direct dependence of a firm's marginal cost on its sectoral relative price, because of an "expenditure switching effect." This effect shows up in the third and fourth terms on the righthand-side of (15). A higher sectoral relative price implies lower demand for the sector's output, which translates into a lower sectoral wage and thus lower marginal costs. This new positive dependence of a firm's marginal cost on the aggregate price level, and negative dependence on its own sectoral price level produce a non-uniform strategic interaction in pricing decisions: a strategic complementarity in price setting across sectors $\left(\varphi \eta p_{t}\right.$ term), and a strategic substitutability within sectors $\left(-\varphi \eta p_{k, t}\right.$ term). The strength of these pricing interactions depends on the degree of substitutability between varieties in different sectors, and on the elasticity of sectoral labor supply, which jointly determine to what extent sectoral wages respond to changes in sectoral relative prices.

The combination of intermediate inputs with sectoral labor market segmentation endows the model with the ability to produce various configurations of within-sector and across-sector pricing interactions. This can be seen from the equation for the frictionless optimal price in the general case $(\delta, \varphi>0)$ :

$$
\begin{aligned}
p_{k, t}^{* *}(i)= & \frac{(1-\delta)\left(1+\varphi-\delta \frac{\theta-1}{\theta} \varphi\right)}{1+\delta \varphi} m_{t} \\
& +\left(1+\delta \varphi-(1-\delta)\left(1+\varphi-\delta \frac{\theta-1}{\theta} \varphi-\varphi \eta\right)\right) p_{t}-\frac{1-\delta}{1+\delta \varphi} \varphi \eta p_{k, t} \\
& +\frac{(1-\delta) \delta \frac{\theta-1}{\theta} \varphi}{1+\delta \varphi} z_{t}+\frac{(1-\delta) \varphi}{1+\delta \varphi} d_{k, t}-\frac{1+\varphi}{1+\delta \varphi}\left(a_{t}+a_{k, t}\right) .
\end{aligned}
$$

\subsubsection{Economy-wide labor market}

A version of the model with an economy-wide labor market does not have the flexibility to produce different configurations of within-sector and across-sector pricing interactions. In the absence of intermediate inputs, it produces strategic substitutability uniformly across all pricing decisions (unless 
one assumes linear disutility of labor, in which case it produces strategic neutrality). ${ }^{13}$ Intermediate inputs move the model toward generating uniform pricing complementarities.

\subsubsection{Firm-specific labor}

A model with firm-specific labor leads to the following equation for the frictionless optimal price: ${ }^{14}$

$$
\begin{aligned}
p_{k, t}^{* *}(i)= & \frac{(1-\delta)\left(1+\varphi-\delta \frac{\theta-1}{\theta} \varphi\right)}{1+\delta \varphi+(1-\delta) \varphi \theta} m_{t} \\
& +\left(1+\frac{(1-\delta) \varphi(\eta-\theta)-(1-\delta)\left(1+\varphi-\delta \frac{\theta-1}{\theta} \varphi\right)}{1+\delta \varphi+(1-\delta) \varphi \theta}\right) p_{t}+\frac{(1-\delta) \varphi}{1+\delta \varphi+(1-\delta) \varphi \theta}(\theta-\eta) p_{k, t} \\
& +\frac{(1-\delta) \varphi \delta \frac{\theta-1}{\theta}}{1+\delta \varphi+(1-\delta) \varphi \theta} z_{t}+\frac{1-\delta}{1+\delta \varphi+(1-\delta) \varphi \theta} \varphi d_{k, t}-\frac{1+\varphi}{1+\delta \varphi+(1-\delta) \varphi \theta}\left(a_{t}+a_{k, t}\right) .
\end{aligned}
$$

This model can also break the uniformity of pricing interactions as long as the elasticities of substitution between varieties within $(\theta)$ and across $(\eta)$ sectors are different. Under the reasonable assumption that $\theta>\eta$, the model strengthens within-sector complementarities at the expense of across-sector complementarities. Producing either within-sector complementarities that are weaker than across-sector, or within-sector strategic substitutability requires $\theta<\eta$.

\subsubsection{Difference relative to the Gertler and Leahy (2008) model of local labor markets}

Gertler and Leahy (2008) develop a menu-cost model with local labor markets. Labor can flow freely across firms in the same "island," but cannot move across islands. In that dimension this is equivalent to our model of sectoral labor markets. However, the implications of labor segmentation for the nature of pricing interactions in our models are quite different. Here we explain why this is the case.

From the point of view of the response of the economy to "common" (aggregate and island-specific) shocks, the local labor market assumption of Gertler and Leahy (2008) is equivalent to one in which labor is firm-specific and wages are, nevertheless, taken as given. In fact, as Woodford (2003, ch. 3) discusses in detail, such a model with firm-specific labor can alternatively be thought of as featuring an additional continuum of firms producing sub-varieties of each variety of the consumption good, all of which use the same type of labor input hired in a competitive market, and change prices at the same time. These groups of firms, which Woodford refers to as "industries," are akin to the Gertler-Leahy islands. ${ }^{15}$ As is well known, this setup gives rise to strategic complementarities in price setting across

\footnotetext{
${ }^{13}$ Since these results are well known, for brevity we omit the relevant equations and refer the interested reader to Woodford (2003).

${ }^{14}$ While we refer to this model as featuring firm-specific labor, in some contexts it may also be consistent with different intepretations. See our discussion in the next subsection.

${ }^{15}$ In Gertler and Leahy (2008) not all firms in an island necessarily end up changing prices at the same time. However, whenever an island-specific shock hits they all entertain a price change at the same time (subject to the menu cost). Moreover, none of them change prices in periods in which island-specific shocks do not hit. As will become clear
} 
firms in different islands (industries). ${ }^{16}$

In our multi-sector model with labor segmentation, price changes are asynchronized even within a given sector. To gain intuition on the effects of within-sector asynchronization of price changes, consider the case of a positive sectoral productivity shock in a given sector. If price changes are infrequent but fully synchronized in each sector, at some point all firms will respond simultaneously by lowering their prices, selling more and producing more. Moreover, the (common) price that is chosen at that time will remain fixed until the next (synchronized) price change. All else equal, the lower the sectoral price is, the higher are sectoral demand, production, labor input, and wages. The negative dependence of the sectoral wage on the sectoral relative price, coupled with the fact that price changes in the sector are synchronized and infrequent, implies a strategic complementarity of the same kind as in the Gertler and Leahy (2008) model.

Now imagine that price adjustments within the sector are staggered uniformly over time, as in our model. Relative to the full-synchronization case, firms that do not cut prices produce and sell less, and thus demand less (sector-specific) labor. This puts downward pressure on the sectoral wage, and thus induces firms that do change prices to cut them by more than in the case of full synchronization. Moreover, going forward other firms in the sector will adjust their prices while (some of) the first movers keep their prices temporarily fixed. The resulting fluctuations in the relative sectoral price will induce fluctuations in the sectoral wage that are unrelated to the prices chosen by the first movers. ${ }^{17}$ This is exactly what produces the within-sector substitutability in pricing decisions that we highlight in Subsection 3.3. ${ }^{18}$

shortly, the resulting pattern of "synchronization" of pricing decisions is what matters, and turns out to imply pricing complementarities just as in Woodford's model, in which all firms in the industry do change prices at the same time.

${ }^{16}$ The equivalence between firm-specific and "industry-" or "island-specific" labor markets breaks down in the presence of firm-specific shocks that wash out at the industry/island level. In that case the issue of whether a firm's labor demand actually affects the wage that it pays becomes crucial. If labor is trully firm-specific, changes in its demand for labor will affect the wage that it pays, and thus labor attachment will affect the firm's incentives to change prices in response to idiosyncratic shocks. Put in terms of the analysis of Ball and Romer (1990) and Kimball (1995), this amounts to a real rigidity that is internal to the firm, and is a source of $\omega$-type strategic complementarity in price setting (in the notation of Kimball 1995, which is also used by Nakamura and Steinsson 2010). In contrast, if firms are trully atomistic they can each change their labor demand in response to idiosyncratic shocks without affecting the wages that they pay. The latter case, which corresponds to Gertler and Leahy (2008), amounts to a real rigidity that is external to the firm, and is a source of $\Omega$-type strategic complementarity in price setting. This is why the assumption of labor segmentation does not hurt the ability of Gertler and Leahy's model to match the size of price changes observed in the data under reasonable parameter values. On that point see also the discussion in Nakamura and Steinsson (2010).

${ }^{17}$ This is in contrast with the case of full synchronization, in which the sectoral price remains fixed until the next episode of synchronized price changes in the sector. In that case the initial price-setting decisions keep influencing what happens to the sectoral wage as long as the sectoral price level remains constant.

${ }^{18}$ Another way to make sense of the implications of our assumption of sectoral labor markets with asynchronized price changes is as follows. As in the model with an economy-wide labor market, pricing decisions of firms that share the same labor input are strategic substitutes. What those two assumptions add, then, is an expenditure switching effect that pushes toward across-sector strategic complementarity, as discussed previously. 


\section{Empirical sectoral price facts}

\subsection{BGM FAVAR}

We start with results based on BGM's FAVAR, using the exact same specification and data. ${ }^{19}$ Figures 1-2 present the IRFs obtained from their FAVAR. The left figure shows the responses of sectoral PCE prices (red dotted lines) to an innovation to the common component in their dynamic factor model, and the corresponding unweighted average of the IRFs (black solid line). The right figure shows the responses of sectoral PCE prices to an innovation to their respective sector-specific components (red dotted lines), and the corresponding unweighted average of the IRFs (black solid line). The responses are scaled so that the initial impact equals minus one for all series. ${ }^{20}$

Figures 1-2: Empirical IRFs - FAVAR
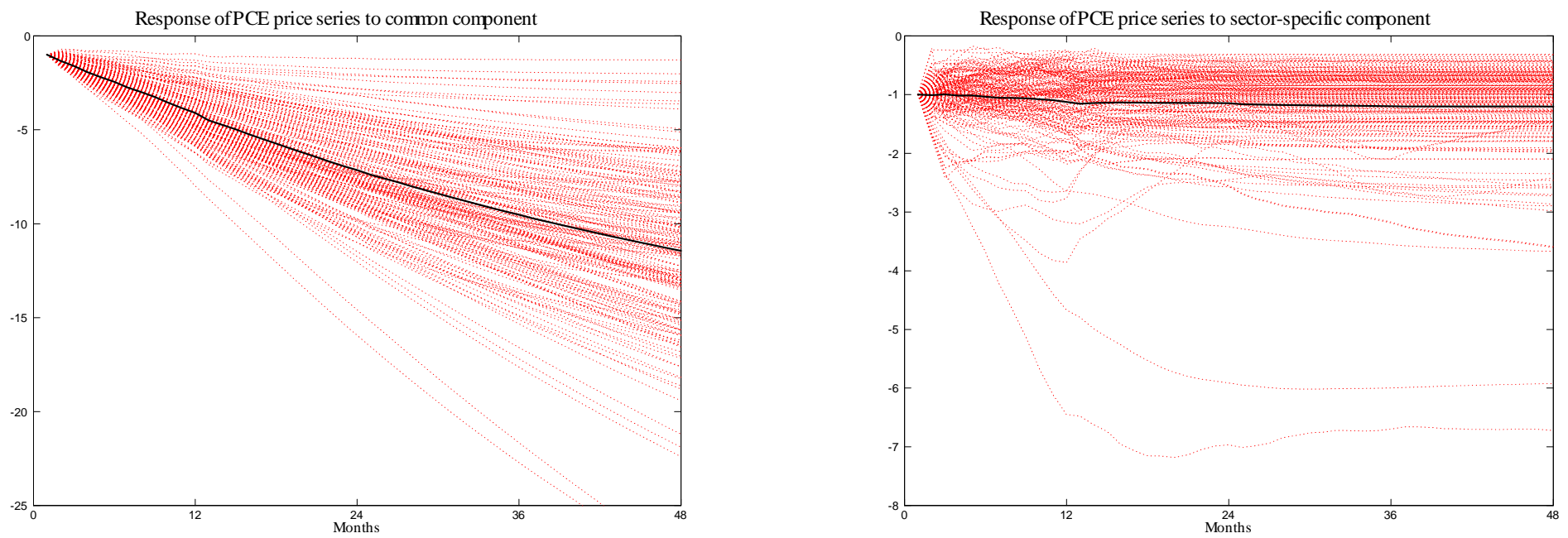

From these IRFs we compute measures of the speed of the price responses to each component, following Maćkowiak et al. (2009). Given an impulse response function denoted $I R F_{t}$, the speed of the response is given by the ratio of the average "short-run" response (first 6 months) to the average "long-run" response (last 6 months in the two-year horizon):

$$
\text { speed of response }=\frac{\sum_{t=0}^{5}\left|I R F_{t}\right|}{\sum_{t=19}^{24}\left|I R F_{t}\right|} .
$$

Figures 3-4 show the distribution of the speed of the responses of sectoral prices to an innovation to the common component (left figure), and to their respective sector-specific components (right figure). Table 1 reports some descriptive statistics based on these two distributions.

\footnotetext{
${ }^{19}$ We thank the authors for making their code and data available on their websites. We also thank Marc Giannoni for providing us with their mapping between the disaggregated PCE price data and the Bils and Klenow (2004) statistics on the frequency of price changes. For brevity we refer the reader to BGM for details on the FAVAR model that they employ.

${ }^{20}$ We apply the same normalization to all IRFs presented subsequently.
} 
Figures 3-4: Cross-sectional distribution of speed of responses
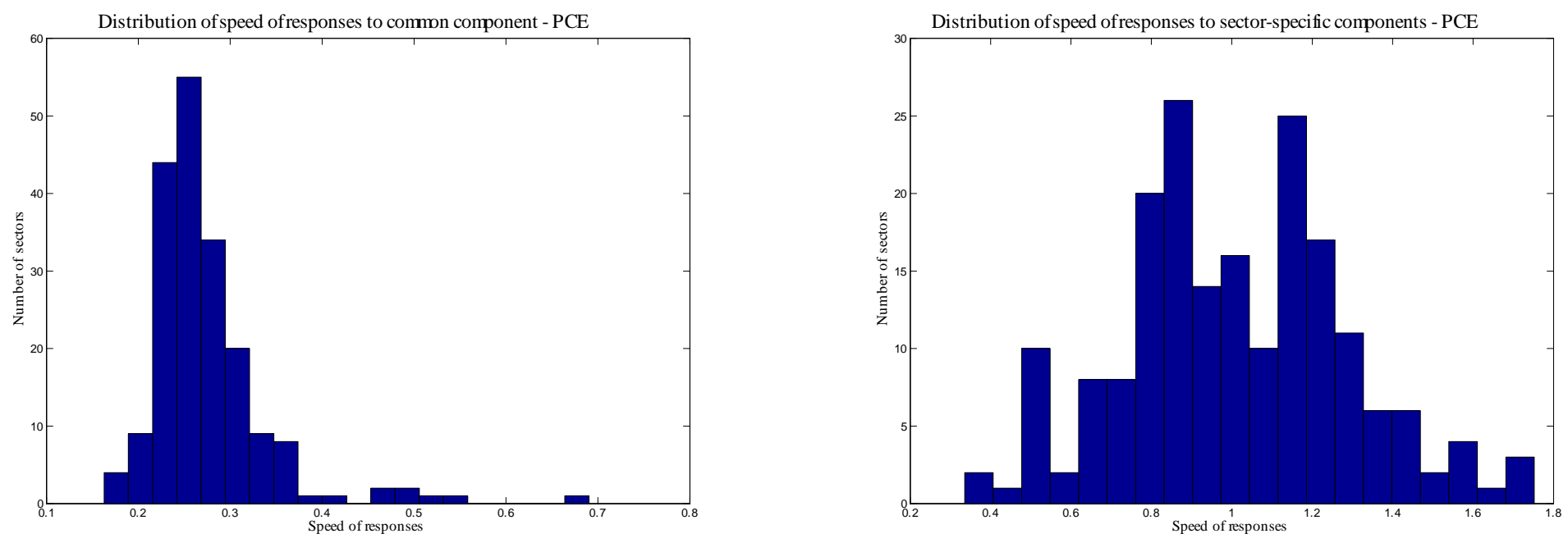

Table 1: Statistics on the speed of responses to shocks

\begin{tabular}{ccc}
\hline \hline & \multicolumn{2}{c}{ Speed of response } \\
& to common & to specific \\
component & components \\
Average & 0.274 & 1.010 \\
Median & 0.261 & 1.001 \\
Std. deviation & 0.066 & 0.281 \\
Coeff. of variation & 0.239 & 0.278 \\
Corr.with 1 $-\alpha_{k}$ & $0.422^{1)}$ & $0.188^{1)}$ \\
Correlation & - & - \\
\hline Note: 1 ) based on a mapping between 108 (out of the 192) PCE price \\
series included in BGM's FAVAR and the Bils and Klenow (2004) \\
statistics on the frequency of price changes.
\end{tabular}

The average speed of response of sectoral prices to sector-specific components is substantially higher than to common components. This conclusion is common to BGM and Maćkowiak et al. (2009). The correlation between the sectoral speeds of responses and the sectoral frequencies of price changes is positive for both the common and sector-specific components. It is higher for the common component (0.42 vs. 0.19). This is consistent with related regression results reported by Maćkowiak et al. (2009). A novel price fact is that the correlation between the speed of responses to both types of shocks is positive: sectors that respond quickly to sector-specific shocks also respond quickly to common shocks. In BGM's FAVAR this correlation is 0.31 .

If measured by the standard deviation, the cross-sectional dispersion in the speed of the responses to common shocks is smaller than the dispersion in the speed of the responses to specific shocks. This essentially reflects the different central tendencies of the two cross-sectional distributions, as the coefficients of variation of the two distributions are quite similar. ${ }^{21}$

\footnotetext{
${ }^{21}$ Our finding on the cross-sectional dispersion of the speed of responses is at odds with the results of Maćkowiak et al. (2009). They conclude that "the cross-section of the speed of response to sector-specific shocks is tight, while the cross-section of the speed of response to aggregate shocks is dispersed." We conjecture that the discrepancy is due
} 
Finally, we reproduce BGM's results on the cross-section of correlations between the sector-specific component of PCE inflation rates and the corresponding sector-specific component of quantities (in growth rates), and the cross-section of correlations between the component of PCE inflation rates and growth rate of quantities that are driven by the common components. These are depicted in Figures 5-6. Table 2 provides summary statistics. The main finding is that most correlations are negative. This led BGM to conclude that supply-type shocks are relatively more important drivers of fluctuations in prices and quantities. This is a conjecture we verify below.

Figures 5-6: Cross-section of correlations between components of prices and quantities

Correlations of sector-specific components of PCE prices and quantities
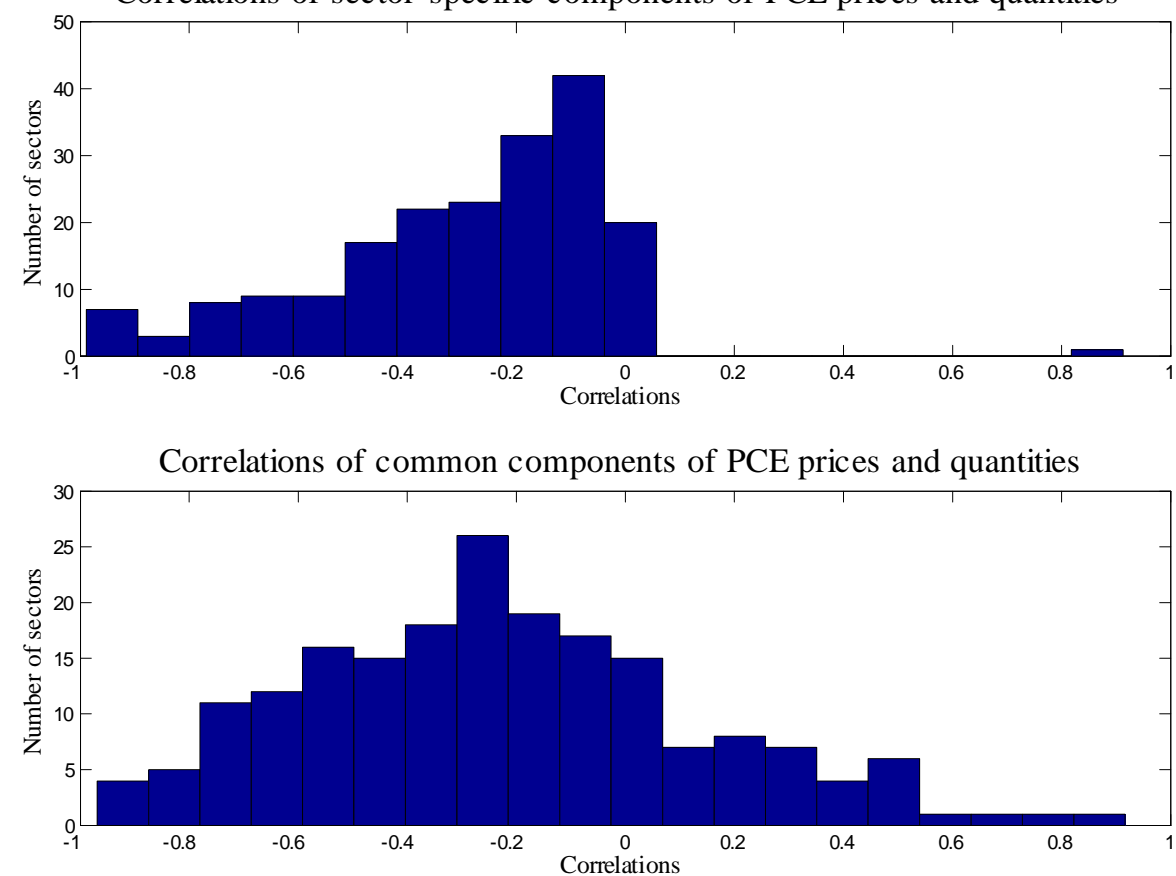

\subsection{5-sector FAVAR}

In our structural estimation in Section 5.2, for computational reasons we use the second-level disaggregation of the PCE data, which consists of 15 sectors. To allow a more direct comparison between our structural and reduced-form empirical results, here we redo the FAVAR analysis of the previous subsection using only the data that we include in the structural estimation. The observables are the

to differences in empirical methodology between their paper and BGM's. A first difference between the two papers is that BGM's dataset includes sectoral quantities and other macroeconomic and financial variables besides price series, whereas Maćkowiak et al. (2009) only use sectoral inflation data. In terms of modeling assumptions, BGM allow for as many as 5 unobserved common factors in their estimation, and impose a vector-autoregressive structure on all of them. They impose weak regularity conditions on the sector-specific components. In contrast, Maćkowiak et al. (2009) impose one common inflation component, and assume time-series processes of different families for their sectoral and common components: while the sectoral components follow AR(6) processes, the common component follows an MA(24) process. Maćkowiak et al.'s (2009) robustness analysis, showing that their results are somewhat sensitive to the number of common factors (section 6.3 of their paper), hints that these differences in modeling assumptions might be important. Finally, Maćkowiak et al. (2009) use a Bayesian approach, whereas BGM use a classical estimation approach. We believe this set of methodological differences between the two papers is potentially important, and their implications should be further investigated in future research. 
Table 2: Statistics on the correlations between components of prices and quantities

\begin{tabular}{|c|c|c|}
\hline & \multicolumn{2}{|c|}{$\begin{array}{l}\text { Correlation between inflation } \\
\text { and growth of quantities }\end{array}$} \\
\hline & $\begin{array}{l}\text { Common } \\
\text { component }\end{array}$ & $\begin{array}{l}\text { Specific } \\
\text { components }\end{array}$ \\
\hline Average & -0.229 & -0.296 \\
\hline Median & -0.260 & -0.239 \\
\hline Max. & 0.917 & 0.913 \\
\hline Min. & -0.969 & -0.990 \\
\hline
\end{tabular}

nominal interest rate $\left(i_{t}\right)$, hours growth $\left(\Delta h_{t}\right)$, and all sectoral inflation and sectoral consumption growth rates $\left\{\pi_{k, t}, \Delta c_{k, t}\right\}_{k=1}^{K}$. We use total hours from the nonfarm business sector as a measure of hours, and the effective federal funds rate as the nominal interest rate. Consumption is given by personal consumption expenditures (PCE), with the corresponding price deflators as the measure of prices. We otherwise keep the same parameterization of the BGM FAVAR model (5 common factors, 13 lags in the VAR). The data are monthly, and the sample period is 1983:M1 to 2008:M12. In the Appendix we present details of the sectors used in the estimation.

Figures 7-12 and Tables 3-4 report the results analogous to those in Figures 1-6 and Tables 1-2. The correlations between the speeds of responses and the frequencies of price changes are based on our mapping of the price-setting statistics for posted prices reported by Nakamura and Steinsson (2008) to the 15-sector disaggregation of the PCE data.

Figures 7-8: Empirical IRFs - FAVAR
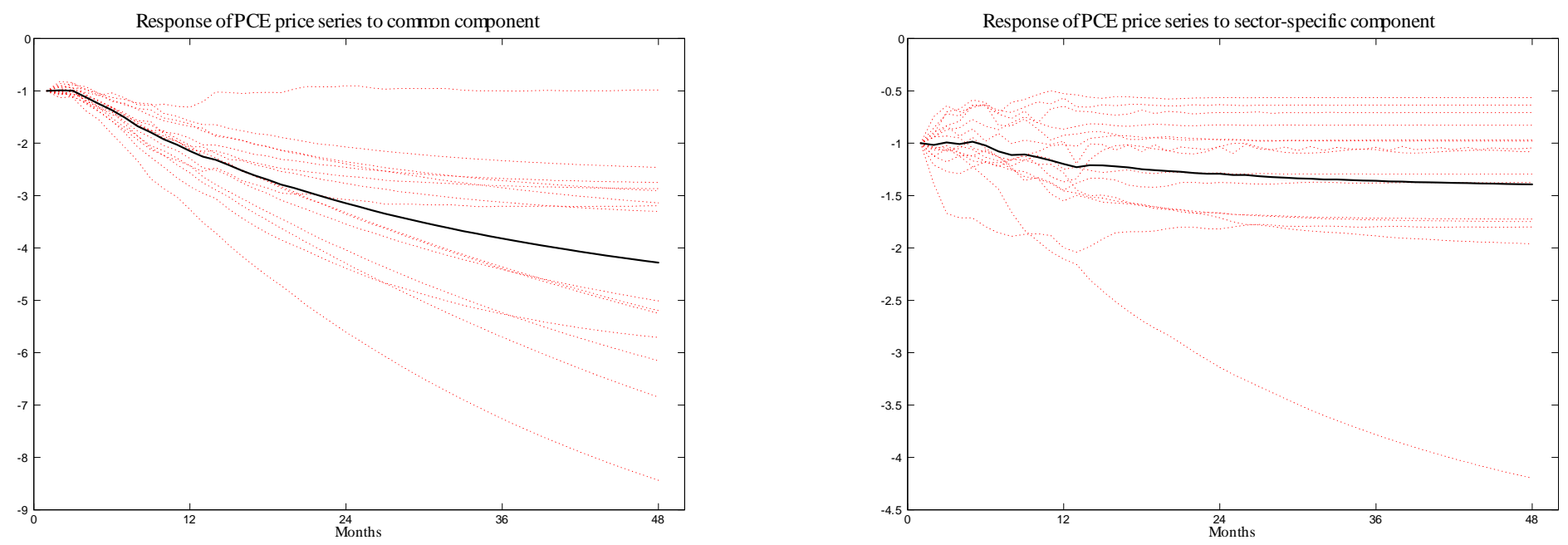
Figures 9-10: Cross-sectional distribution of speed of responses
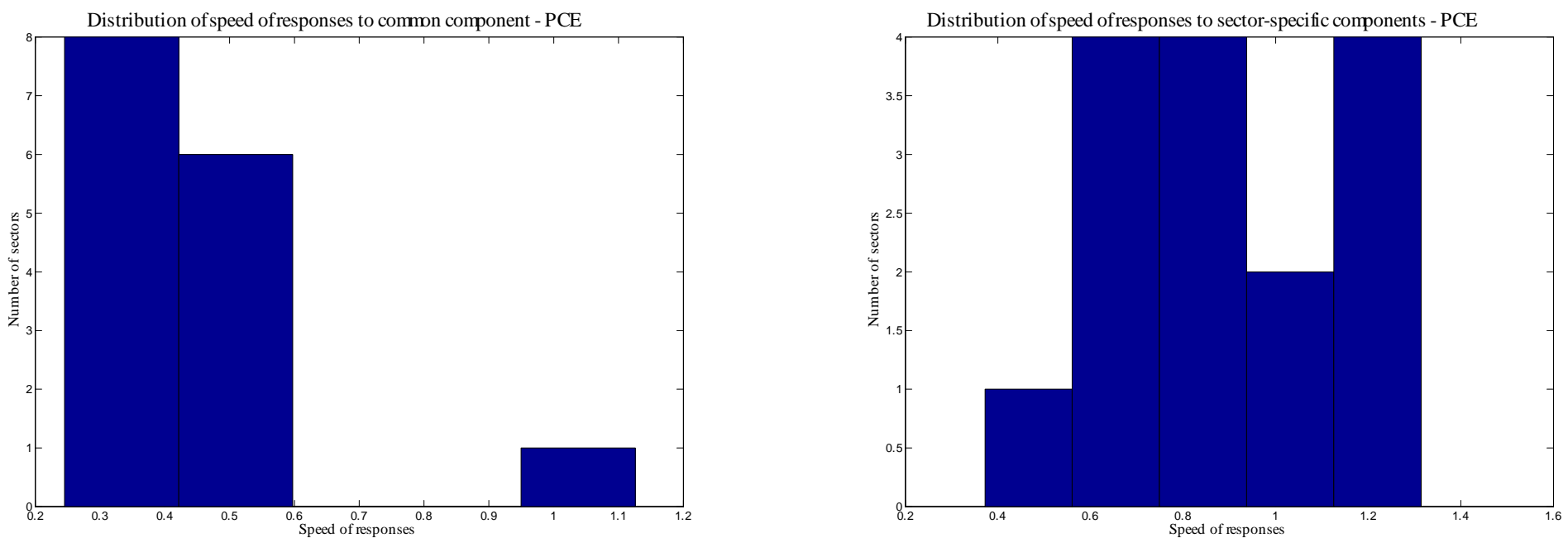

Table 3: Statistics on the speed of responses to shocks - 15-sector FAVAR

\begin{tabular}{|c|c|c|c|}
\hline & \multicolumn{3}{|c|}{ Speed of response } \\
\hline & to common & & to specific \\
\hline & component & & components \\
\hline Average & 0.423 & & 0.889 \\
\hline Median & 0.397 & & 0.855 \\
\hline Std. deviation & 0.208 & & 0.269 \\
\hline Coeff. of variation & 0.491 & & 0.303 \\
\hline Corr.with $1-\alpha_{k}$ & 0.755 & & 0.331 \\
\hline Correlation & - & 0.350 & - \\
\hline
\end{tabular}

Table 4: Statistics on the correlations between components of prices and quantities - 15-sector FAVAR

\begin{tabular}{ccc}
\hline \hline & \multicolumn{2}{c}{ Correlation between inflation } \\
& and growth of quantities \\
& Common & Specific \\
& component & components \\
Average & -0.327 & -0.109 \\
Median & -0.331 & -0.149 \\
Max. & 0.201 & 0.144 \\
Min. & -0.932 & -0.394 \\
\hline
\end{tabular}


Figures 11-12: Cross-section of correlations between components of prices and quantities Correlations of sector-specific components of PCE prices and quantities

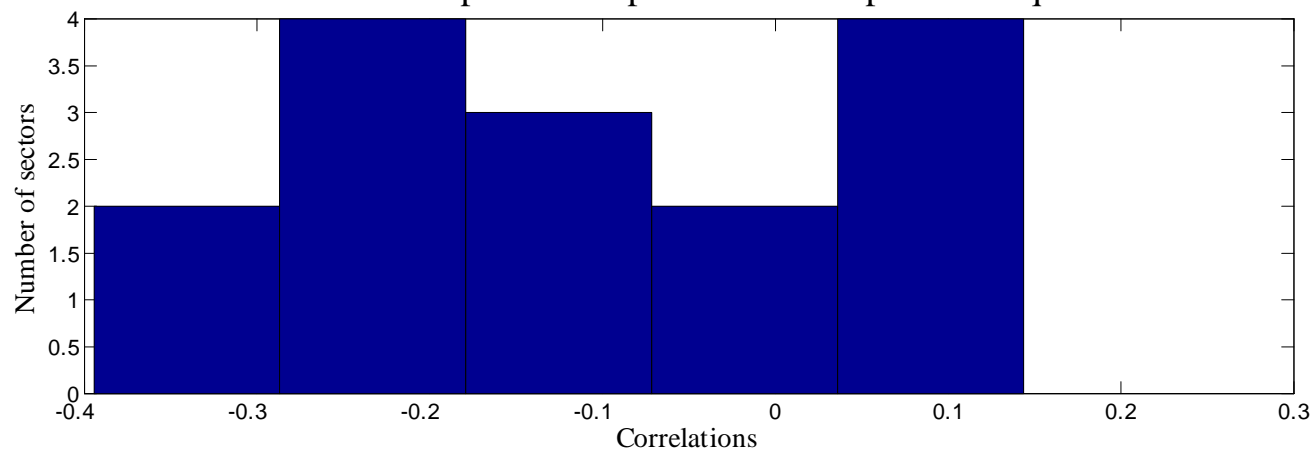

Correlations of common components of PCE prices and quantities

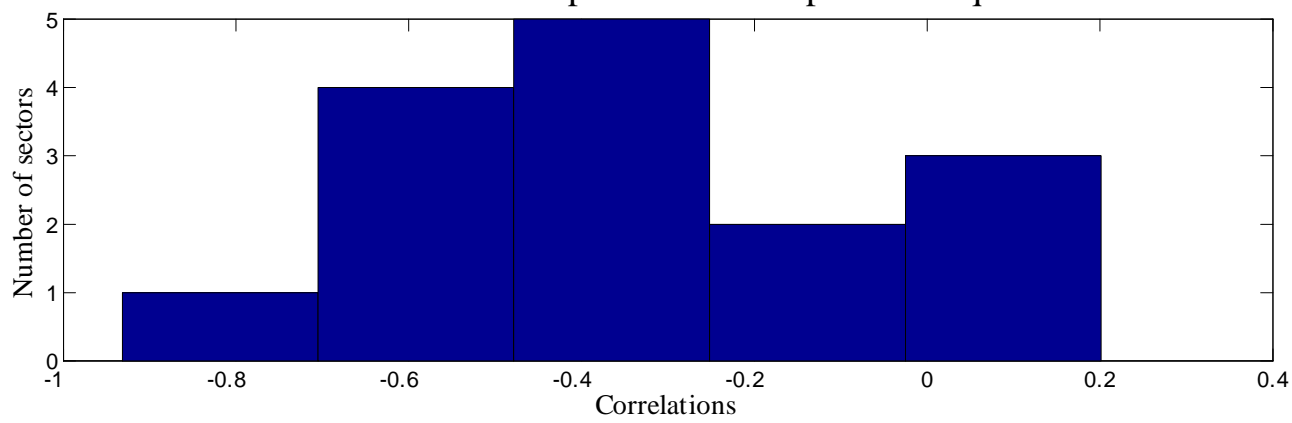

\subsection{Summary}

The results are quite similar across the two FAVAR specifications. Moreover, in our robustness analysis (reported in the Appendix) we show that these findings also hold in a FAVAR with 50 sectors, corresponding to the third level of disaggregation of the PCE data. We thus summarize the empirical evidence with the following facts: i) the average speed of response of sectoral prices to sector-specific shocks is higher than the average speed of response to shocks to the common component (by a factor of $2-4)$; ii) The correlation between the sectoral speeds of responses and the sectoral frequencies of price changes is positive for both the common and sector-specific components - it is higher for the common component; iii) The correlation between the speed of responses to both types of shocks is positive; iv) the cross-sectional standard deviation of the sectoral speeds of responses to shocks to the common component is smaller than the corresponding standard deviation for the responses to sector-specific shocks; v) the cross-sectional mean of the correlations between the sector-specific component of PCE infation rates and the corresponding sector-specific component of the growth rate in quantities is negative - the same applies to the fluctuations that are driven by the common component. 


\section{Quantitative analysis}

We focus on the model in which monetary policy responds to endogenous variables according to a Taylor-type interest-rate rule. To simulate (and subsequently estimate) the model, it is necessary to make distributional assumptions on the exogenous shocks. We assume they follow AR(1) processes:

$$
\begin{aligned}
\gamma_{t+1} & =\rho_{\Gamma} \gamma_{t}+\sigma_{\Gamma} \varepsilon_{\Gamma, t+1}, \\
a_{t+1} & =\rho_{A} a_{t}+\sigma_{A} \varepsilon_{A, t+1}, \\
\mu_{t+1} & =\rho_{\mu} \mu_{t}+\sigma_{\mu} \varepsilon_{\mu, t+1}, \\
a_{k, t+1} & =\rho_{A_{k}} a_{k, t}+\sigma_{A_{k}} \varepsilon_{A_{k}, t+1}, \\
d_{k, t+1} & =\widetilde{d}_{k, t+1}-\sum_{k=1}^{K} n_{k} \widetilde{d}_{k, t}, \text { where } \widetilde{d}_{k, t+1}=\rho_{D_{k}} \widetilde{d}_{k, t}+\sigma_{D_{k}} \varepsilon_{D_{k}, t+1},
\end{aligned}
$$

with every innovation being standard Gaussian white noise.

As a preliminary step, in the next subsection we study the properties of a simply parameterized version of the model to assess whether it can endogenously produce meaningful differences in the speed of responses of sectoral prices to aggregate and sectoral shocks. We present both results obtained directly from the solution of the model (what we refer to as "model-implied results"), and results obtained by estimating a FAVAR on model-generated data. We then move to the estimation of the model using Bayesian methods, which is the basis for our ultimate quantitative analysis.

\subsection{Preliminaries}

\subsubsection{Model parameterization}

As highlighted in Section 3, the speed of the adjustment of sectoral prices depends on the specification of the dynamics of the exogenous shocks. To isolate the differential response of sectoral prices to aggregate and sectoral shocks delivered endogenously by the model, here we assume that every exogenous shock has the same degree of persistence. Assuming the unit of time is one month, we set every autoregressive coefficient to be $0.9^{1 / 3}$. In Section 5.2 we estimate the parameters of the shock processes maintaining the $\operatorname{AR}(1)$ assumption.

We set the other parameters to conventional values found in the literature. The discount factor, $\beta$, equals 0.9967 , corresponding to a $4 \%$ annual steady-state interest rate. The parameter $\varphi$ is set equal to 2 so that the (Frisch) elasticity of labor supply is 0.5 . We set the within-sector elasticity of substitution between different varieties, $\theta$, to 6 , which implies a 20 percent steady-state mark-up for the firms. The across-sector elasticity of substitution, $\eta$, is set equal to 2 . The elasticity of output with respect to intermediate inputs, $\delta$, is set to 0.7 . We adopt standard values for the policy parameters, setting $\phi_{\pi}$ and $\phi_{c}$ equal to 1.5 and $0.5 / 12$, respectively.

The size of the shocks does not matter for the results based on "theoretical" impulse response functions (i.e. those obtained from the solution of the model). But it does matter for the results obtained by estimating a FAVAR on model-generated data, due to the reduced-form nature of the estimated shocks. For the aggregate productivity and preference shocks we assume a standard de- 
viation of $0.01 / \sqrt{3}$ (1\% quarterly); for the monetary shock we assume $0.002 / \sqrt{3}$. Sectoral shocks are likely larger than aggregate shocks. For sectoral demand shocks we assume $\sigma_{D_{k}}=0.025 / \sqrt{3}$, and for sectoral productivity shocks we assume that innovations are three times as volatile, and set $\sigma_{A_{k}}=0.075 / \sqrt{3} .^{22}$

We simulate the parameterized economy with 50 sectors, mirroring the third-level disaggregation of PCE data. The corresponding distribution of price stickiness is constructed by suitably aggregating consumption categories from the Nakamura and Steinsson (2008) price-setting statistics. The sectoral weights are the PCE expenditure weights averaged over our sample period.

\subsubsection{Model-implied results}

We start with results taken directly from the solution of the parameterized model. Figures 1314 present the theoretical IRFs of sectoral prices to an aggregate productivity shock, and to the respective sectoral productivity shocks. In the sequence, Figures 15-16 show the distributions of the speed of the responses to an aggregate productivity shock (left figure), and to the respective sectorspecific productivity shocks (right figure). Table 5 reports descriptive statistics based on these two distributions.

Figures 13-14: Theoretical IRFs
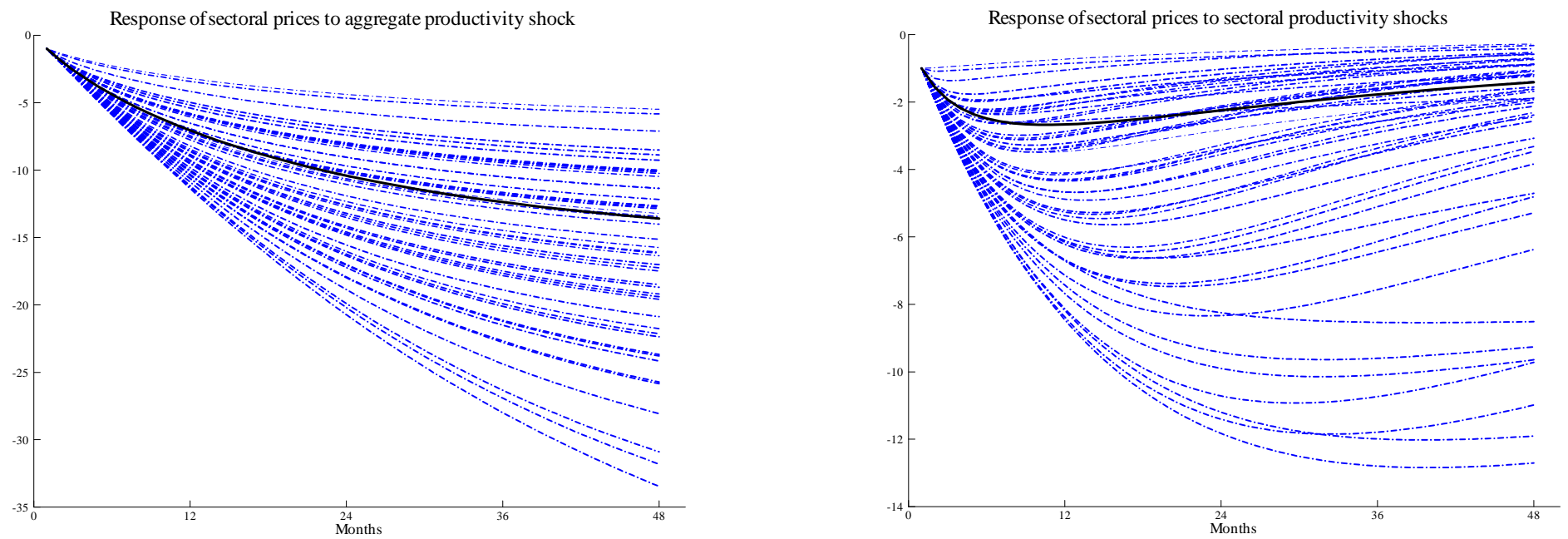

The cross-sectional distributions of the speed of responses to both shocks, calculated according to (16), are shown in Figures 15-16. Summary statistics are provided in Table 5.

\footnotetext{
${ }^{22}$ This is motivated by the results in Burstein and Hellwig (2008).
} 
Table 5: Speed of response to productivity shocks

\begin{tabular}{|c|c|c|c|}
\hline & \multicolumn{3}{|c|}{ Speed of response } \\
\hline & $\begin{array}{l}\text { to aggregate } \\
\text { shock }\end{array}$ & & $\begin{array}{l}\text { to sectoral } \\
\text { shock }\end{array}$ \\
\hline Average & 0.273 & & 0.808 \\
\hline Median & 0.266 & & 0.725 \\
\hline Std. deviation & 0.060 & & 0.399 \\
\hline Coeff. of variation & 0.219 & & 0.493 \\
\hline Corr.with $1-\alpha_{k}$ & 0.862 & & 0.877 \\
\hline Correlation & - & 0.971 & - \\
\hline
\end{tabular}

Figures 15-16: Cross-sectional distribution of speed of responses
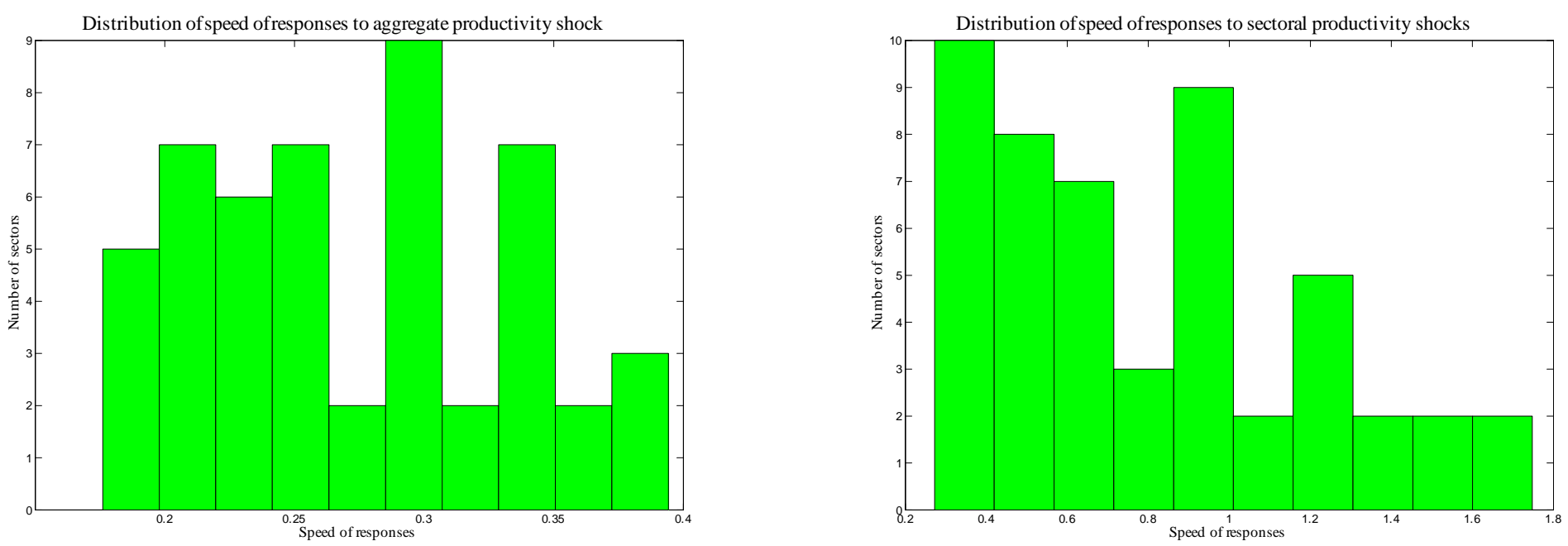

The results illustrate the potential of the model to deliver relatively faster responses of sectoral prices to sector-specific productivity shocks, when compared to aggregate productivity shocks. ${ }^{23}$ Given that all shocks are assumed to follow the same exogenous dynamics, these results reflect the ability of the parameterized model to produce such differential responses endogenously. The model also endogenously produces less dispersion in the speed of responses of sectoral prices to the aggregate shock when compared to the responses to sectoral shocks. ${ }^{24}$ This result arises naturally from the pattern of pricing complementarities and substitutabilities implied by our model, which produces relatively stronger comovement of sectoral prices in response to aggregate shocks (see the discussion in Section 3).

This simply parameterized model also produces the right signs for the correlations between the speed of responses to shocks and the frequencies of price changes, and for the correlation between the speeds of responses to the two types of shocks. However, because the dynamics of the exogenous shocks are identical, heterogeneity in the frequency of price changes is the only relevant source of differences across sectors. As a result, there is a very tight link between the speeds of responses to

\footnotetext{
${ }^{23}$ The patterns with other types of shocks are similar.

${ }^{24}$ Recall that in the first-pass specification without the three "ingredients" discussed in detail in Section (3), the impulse response functions of sectoral prices to both types of shocks are indentical. As a result, the cross-sectional distributions of the speeds of responses to both types of shocks are also identical.
} 
aggregate and sectoral shocks and the frequencies of price changes, which is apparent in the very high correlations reported in Table 5 .

The role of each "ingredient" We also analyze the model by introducing each of the three ingredients discussed in Section 3 at a time into the first-pass specification with strategic neutrality in price setting and exogenous monetary policy. We then combine the Taylor rule with each of the other two ingredients. In quantitative terms, labor-market segmentation seems to be the main driving force behind the ability of the model to produce price responses to sectoral shocks that are fast in an absolute sense. However, without endogenous monetary policy and intermediate inputs the absolute level of the speeds of responses is too high relative to the data. For brevity we present the details of this analysis in the Appendix, and from now on we focus on the quantitative performance of the model with all three ingredients.

\subsubsection{FAVAR results with model-generated data}

While the results of the previous subsection involve responses conditional on particular shocks, the empirical evidence that we summarize in Subsection 4 involves responses to shocks extracted from the statistical FAVAR framework. As such, they can be thought of as involving a combination of structural shocks. To produce results from the model that are more comparable to the empirical evidence, we estimate a FAVAR on data generated by simulating the model with all the shocks, and produce the results underlying figures and tables in the exact same way as in Subsection 4 . The artificial dataset comprises consumption growth, inflation, the nominal interest rate, hours growth, and all sectoral inflation and sectoral consumption growth rates. The specification of the FAVAR is identical to the one we estimate for the 15-sector disaggregation of the PCE data (Subsection 4.2).

Figures $17-18$ present the IRFs from the FAVAR estimation on artificial data. ${ }^{25}$

Figures 17-18: IRFs from FAVAR
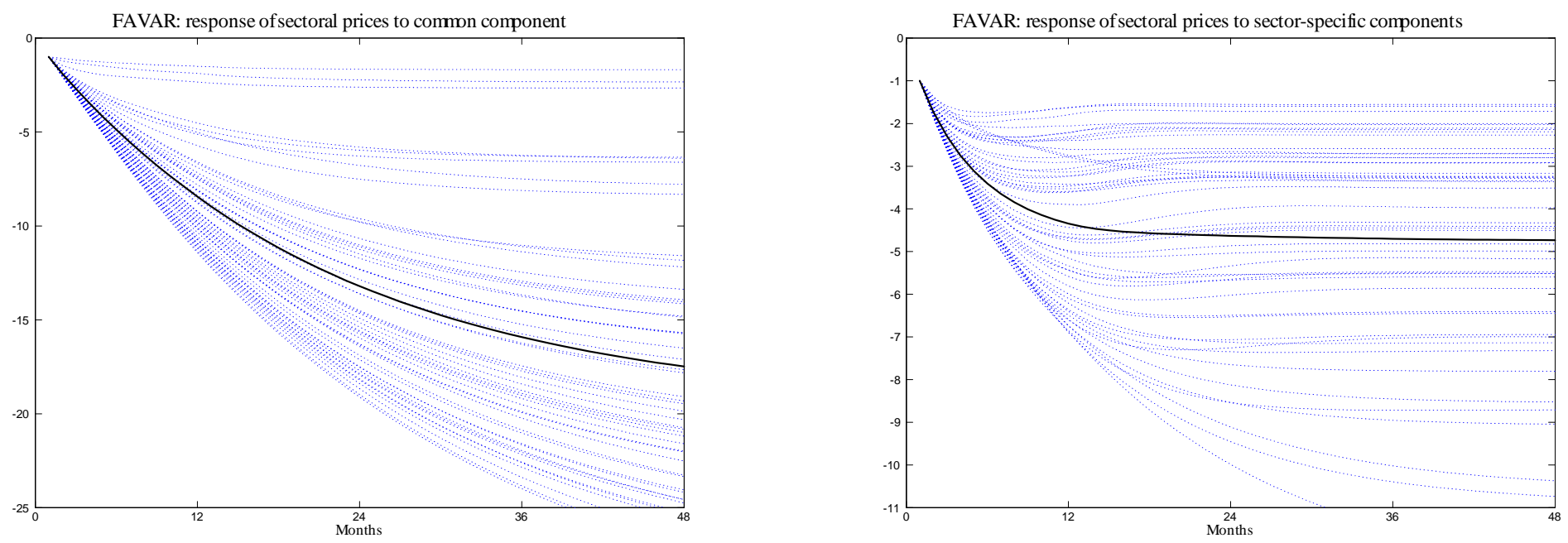

\footnotetext{
${ }^{25}$ We produce a sample with twelve thousand observations and discard the first two thousand to minimize the effects of initial conditions. Drawing different samples of the same size had negligible effects on the results. They can thus be interpreted as "FAVAR-filtered population results."
} 
Figures 19-20 show the distribution of the speed of the price responses to an innovation to the common component (left figure), and to the sector-specific components (right figure). Table 6 reports descriptive statistics based on these two distributions.

Figures 19-20: Cross-sectional distribution of speed of responses
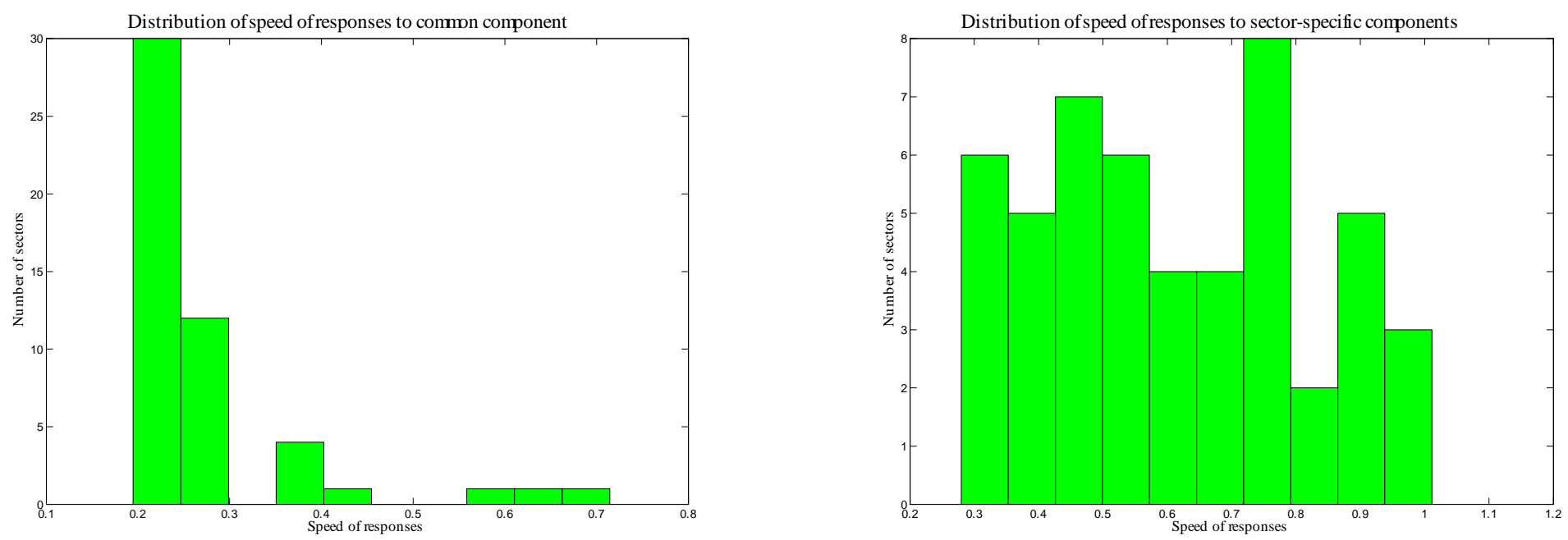

Table 6: Statistics on the speed of responses to shocks

\begin{tabular}{|c|c|c|c|}
\hline & \multicolumn{3}{|c|}{ Speed of response } \\
\hline & to common & & to specific \\
\hline & component & & components \\
\hline Average & 0.271 & & 0.613 \\
\hline Median & 0.227 & & 0.576 \\
\hline Std. deviation & 0.111 & & 0.207 \\
\hline Coeff. of variation & 0.411 & & 0.339 \\
\hline Corr.with $1-\alpha_{k}$ & 0.955 & & 0.527 \\
\hline Correlation & - & 0.438 & - \\
\hline
\end{tabular}

A comparison between Tables 5 and 6 reveals that, qualitatively, the FAVAR framework captures all of implications of our structural model for those sectoral-price statistics. At first this may seem surprising, since the artificial data underlying the results in Table 6 are driven by a variety of shocks. As such, they are not conditional on (aggregate and sectoral) productivity shocks, unlike the modelimplied results reported in Table 5. The reason why conditional and "unconditional" results are somewhat close is that this parameterized model produces similar statistics in response to the other structural shocks.

Finally, we report the results on the cross-section of correlations between the sector-specific component of inflation rates and the corresponding sector-specific component of quantities (in growth rates), and the cross-section of correlations between the component of inflation rates and growth rate of quantities that are driven by the common components. These are depicted in Figures 21-22, and summarized in Table 7. 
Figures 21-22: Cross-section of correlations between components of prices and quantities

Correlations of sector-specific components of PCE prices and quantities
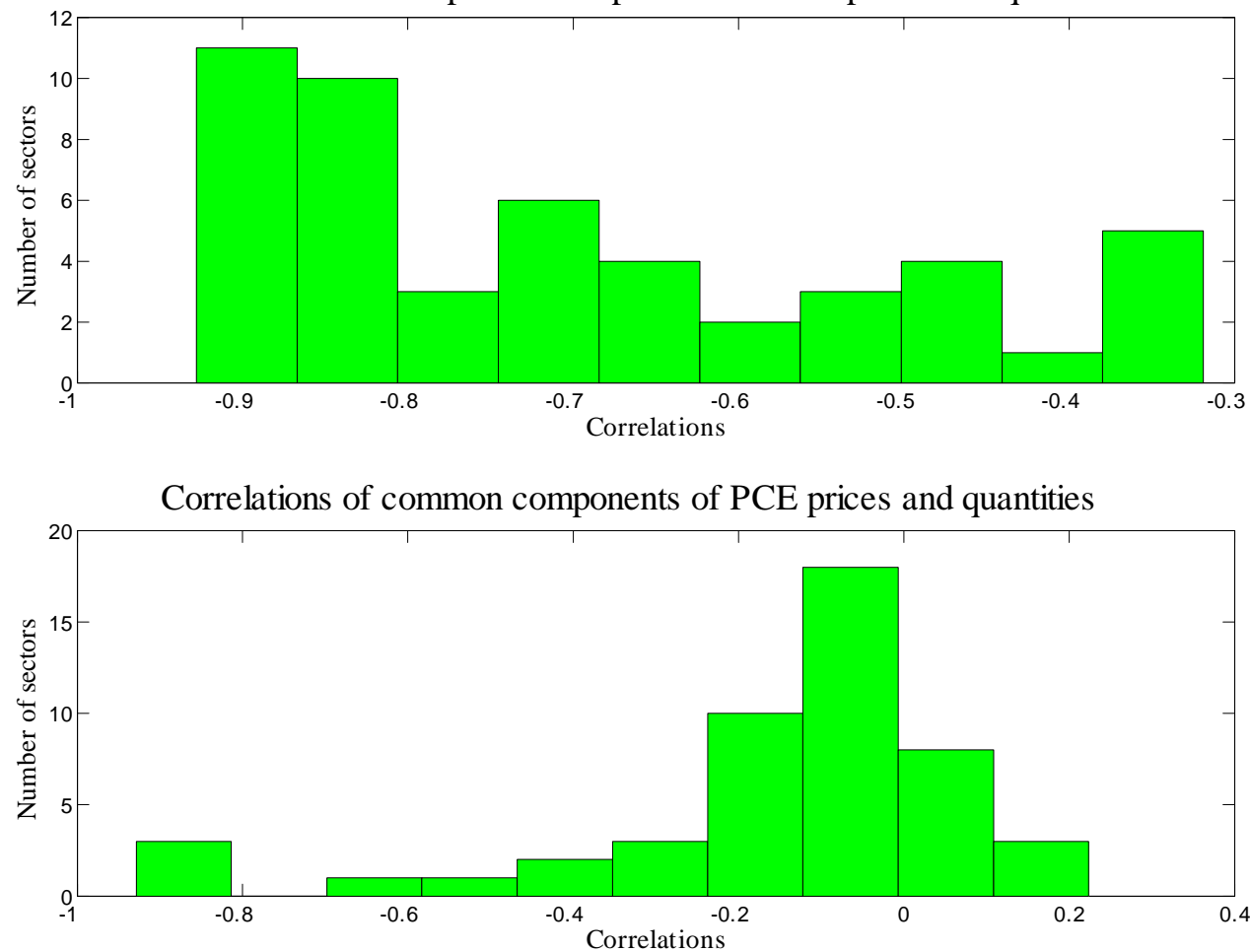

Table 7: Statistics on the correlations between components of prices and quantities

\begin{tabular}{ccc}
\hline \hline & \multicolumn{1}{c}{$\begin{array}{c}\text { Correlation between inflation } \\
\text { and growth of quantities } \\
\text { Common }\end{array}$} & Specific \\
& component & components \\
Average & -0.151 & -0.701 \\
Median & -0.084 & -0.738 \\
Max. & 0.224 & -0.319 \\
Min. & -0.929 & -0.928 \\
\hline
\end{tabular}

Overall, the results show that in response to "reduced-form" sectoral and common shocks extracted through the FAVAR framework, the model manages to produce results that are qualitatively similar to the empirical facts summarized in the previous section. In addition to the statistics on the speed of sectoral price adjustment to shocks, the results on the cross-section of correlations between inflation rates and the growth rates of quantities are also in line with the empirical evidence - in particular the negative correlations between the sector-specific component of inflation rates and the corresponding sector-specific component of the growth rate in quantities. ${ }^{26}$

The quantitative analysis carried out in this and the previous subsections suggests that the model has enough flexibility to produce quantitative results in accordance with the empirical facts summa-

\footnotetext{
${ }^{26}$ In unreported results we confirm BGM's conjecture that such negative correlations arise when supply-type shocks are dominant.
} 
rized in the previous section. This underscores our effort to move to estimation of the structural model in order to assess its ability to match those facts.

\subsection{Model estimation}

Although the parameterized version of the model analyzed in the previous subsections is a useful starting point for a quantitative analysis, it only provides a partial picture about the ability of our model to match the empirical findings reported in Section 4. In particular, because the response of sectoral prices depends on the dynamic properties of exogenous shocks, parameterizing the shocks symmetrically can be problematic.

In this section we estimate the model employing Bayesian methods. We incorporate prior information about the structural parameters $\boldsymbol{\theta}$ by specifying a prior distribution $f(\boldsymbol{\theta})$. With data set $\mathbf{X}^{T}$, we can obtain the likelihood function $f\left(\mathbf{X}^{T} \mid \boldsymbol{\theta}\right)$ implied by the model economy. The posterior distribution of $\boldsymbol{\theta}, f\left(\boldsymbol{\theta} \mid \mathbf{X}^{T}\right)$ is then determined by Bayes theorem: $f\left(\boldsymbol{\theta} \mid \mathbf{X}^{T}\right)=f\left(\mathbf{X}^{T} \mid \boldsymbol{\theta}\right) f(\boldsymbol{\theta}) / \int f\left(\mathbf{X}^{T} \mid \boldsymbol{\theta}\right) f(\boldsymbol{\theta}) d \boldsymbol{\theta}$. We simulate the posterior distribution by Markov Chain Monte Carlo methods as detailed in the Appendix.

We take the model to the aggregate and sectoral data described in Subsection 4.2. We normalize total hours and the sectoral consumption measures by the total civilian non-institutional population over age of 16 . We also detrend the real variables using a linear trend, and demean the nominal interest rate and the sectoral inflation rates. The sectoral weights are set to the expenditure weights averaged over our sample period.

\subsubsection{Priors and posteriors}

We fix some parameters in the estimation, setting the same values as in the parameterized version of the model studied in previous subsections. The fixed parameters are $\beta, \varphi, \theta, \eta, \delta$, and $\left\{\alpha_{k}, n_{k}\right\}_{k=1}^{K}$. As for the remaining parameters, our prior distribution mostly follows the convention in the literature on Bayesian estimation of DSGE models. Regarding the Taylor rule coefficients, we select normal distributions. The mean of $\phi_{\pi}$ is set to be 1.5 with standard deviation of 0.25 . We set the mean of $\phi_{c}$ to be $0.5 / 12$ and its prior standard deviation to be 0.05 . The autoregressive parameter of the monetary shock, $\rho_{\mu}$, has a beta distribution with mean of 0.7 and standard deviation of 0.1 , whereas the innovation parameter, $\sigma_{\mu}$, has an inverse gamma distribution with mean of $0.125 \%$ and standard deviation of $0.125 \%$.

Similarly to the monetary shock, we assume that the autoregressive parameters for the remaining exogenous shocks have a beta distribution and the coefficients on the innovations have an inverse gamma distribution. We treat the aggregate shocks, $\gamma_{t}$ and $a_{t}$, symmetrically. The prior mean of $\rho_{\Gamma}$

and $\rho_{A}$ is 0.7 , and the standard deviation is 0.1 . The standard deviations of the innovations $\sigma_{\Gamma}$ and $\sigma_{A}$ are assumed to have mean of $0.5 \%$ and standard deviation of $0.5 \%$.

We also treat the sectoral shocks symmetrically in the prior distribution. The autoregressive parameters have the same prior distribution as their counterparts in aggregate shocks. However, due to the likely more volatile nature of sectoral shocks, we set the prior mean of $\sigma_{A_{k}}$ and $\sigma_{D_{k}}$ to 
$5 \%$ and the prior standard deviation to $2 \%$. Finally, we assume that all parameters are distributed independently.

The Appendix reports moments of the prior and posterior distributions. The quantitative analysis that follows is based on the posterior means (results with the posterior mode are essentially the same).

\subsubsection{Results}

For comparability with the empirical evidence we present results obtained by estimating a FAVAR on artificial data generated by the model. ${ }^{27}$ The artificial dataset comprises consumption growth, inflation, the nominal interest rate, hours growth, and all sectoral inflation and sectoral consumption growth rates. The specification of the FAVAR is identical to that of Subsection 5.1.3.

Figures 23-24 present the IRFs from the FAVAR estimation on model-generated data.

Figures 23-24: IRFs from FAVAR - 15 sectors
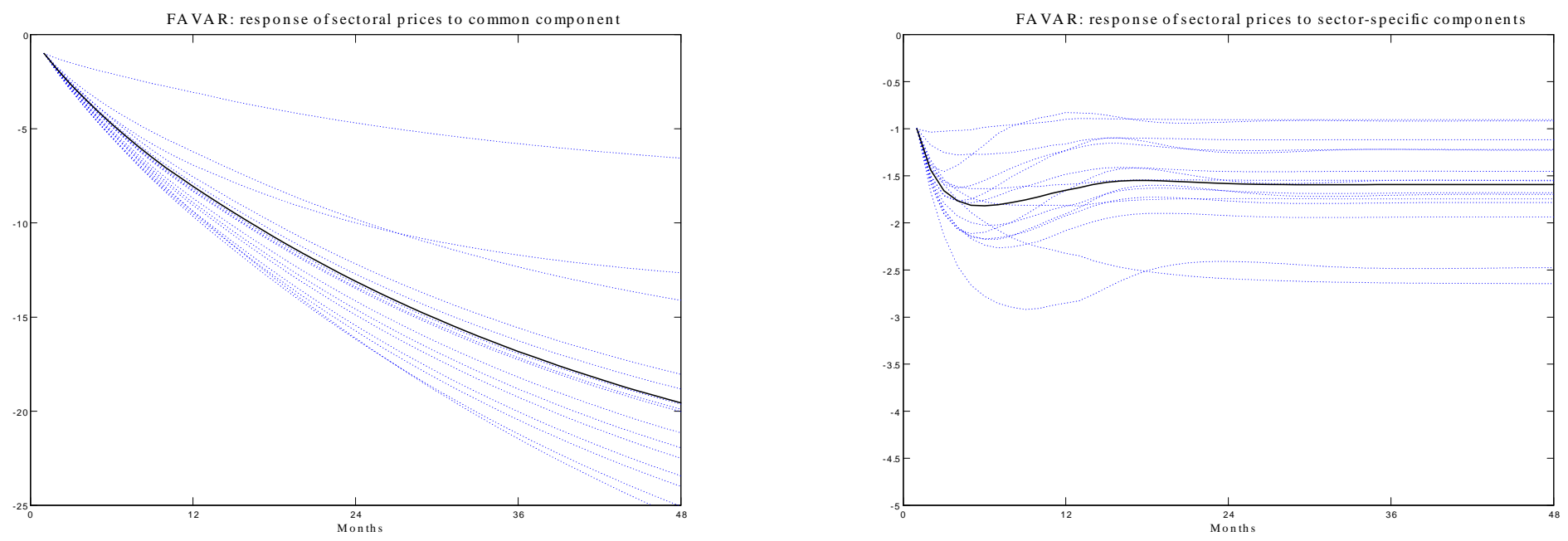

Figures 25-26 show the distribution of the speed of the responses to an innovation to the common component (left figure), and to the sector-specific components (right figure). Table 8 reports descriptive statistics based on these two distributions.

Table 8: Statistics on the speed of responses to shocks - estimated 15-sector model

\begin{tabular}{|c|c|c|c|}
\hline & \multicolumn{3}{|c|}{ Speed of response } \\
\hline & to common & & to specific \\
\hline & component & & components \\
\hline Average & 0.244 & & 1.050 \\
\hline Median & 0.236 & & 1.085 \\
\hline Std. deviation & 0.036 & & 0.184 \\
\hline Coeff. of variation & 0.148 & & 0.175 \\
\hline Corr.with $1-\alpha_{k}$ & 0.702 & & 0.407 \\
\hline Correlation & - & 0.165 & - \\
\hline
\end{tabular}

\footnotetext{
${ }^{27}$ In the Appendix we reproduce the impulse responses of sectoral prices to aggregate and sectoral productivity shocks implied by the estimated model, as well as to the aggregate preference and sectoral demand shocks.
} 
Figures 25-26: Cross-sectional distribution of speed of responses - 15 sectors
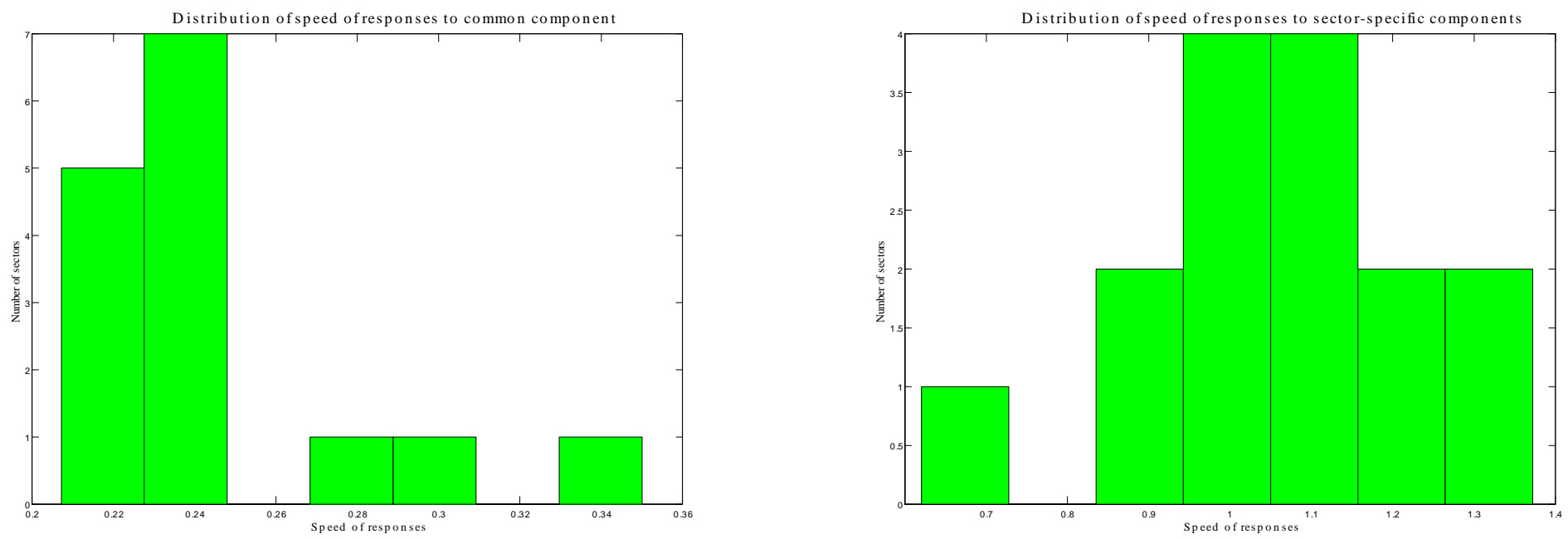

Finally, we report the results that the estimated model produces for the cross-section of correlations between the sector-specific component of inflation rates and the corresponding sector-specific component of quantities (in growth rates), and the cross-section of correlations between the component of inflation rates and growth rate of quantities that are driven by the common components. These are depicted in Figures 27-28, and summarized in Table 9.

Table 9: Statistics on the correlations between components of prices and quantities - estimated 15sector model

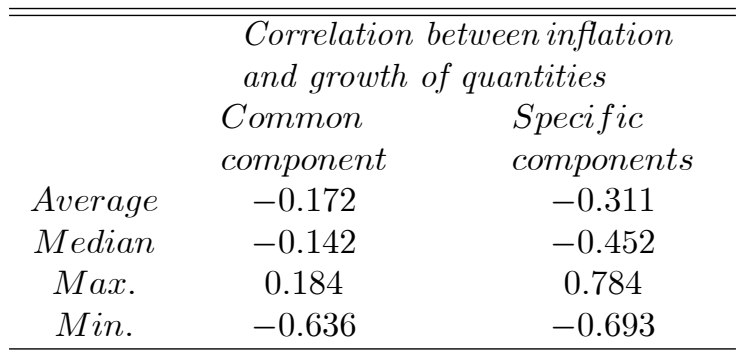


Figures 27-28: Cross-section of correlations between components of prices and quantities - 15 sectors
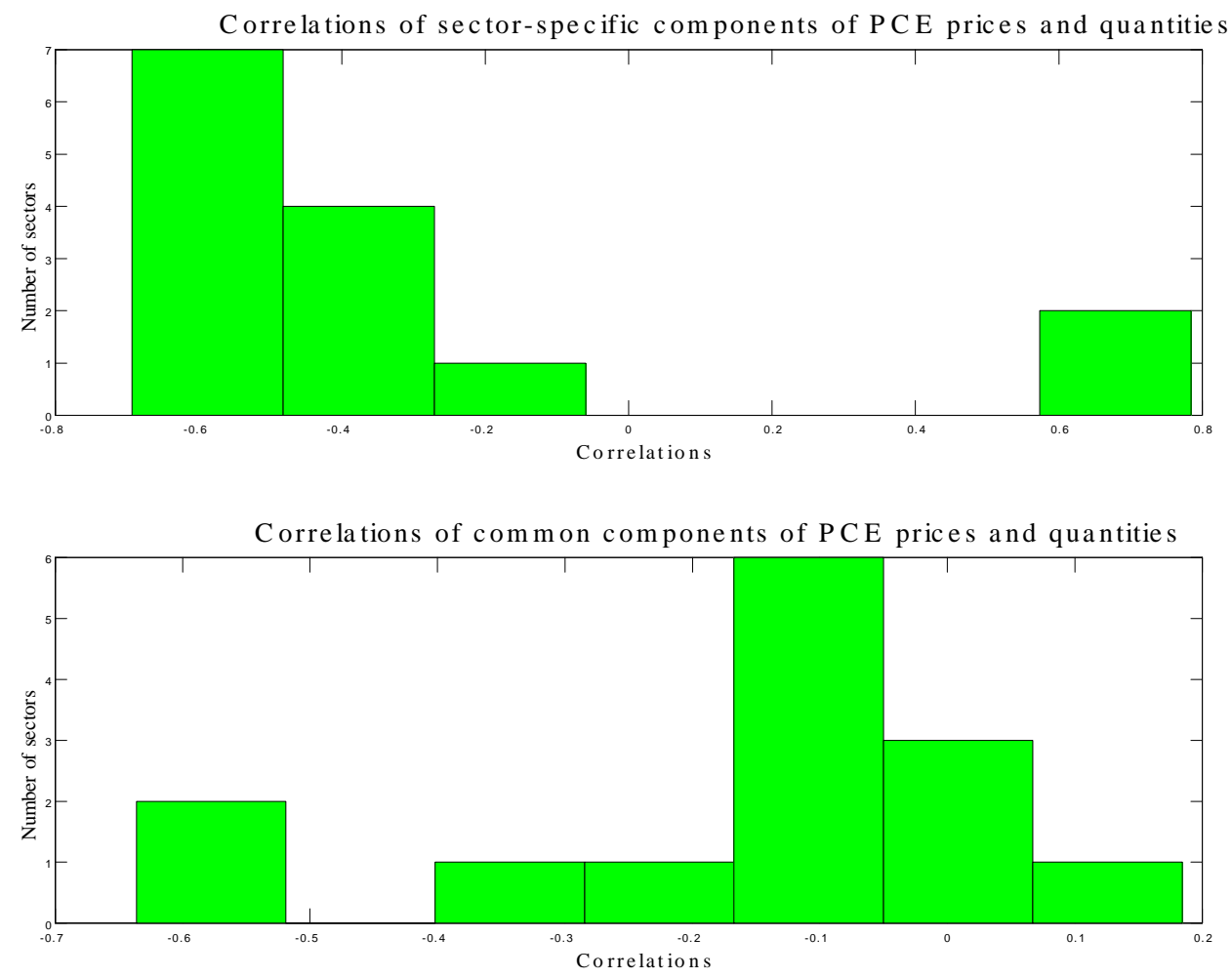

Regarding the joint distribution of the speed of price responses to common and sector-specific components, a comparison of Tables 1 and 8 reveals that the estimated model captures its main features very well. Specifically, i) the average speed of response of sectoral prices to sector-specific shocks is roughly four times higher than the average speed of response to shocks to the common component; ii) The correlation between the sectoral speeds of responses and the sectoral frequencies of price changes is positive for both the common and sector-specific components - it is higher for the common component; iii) The correlation between the speed of responses to both types of shocks is positive; iv) the cross-sectional standard deviation of the sectoral speeds of responses to shocks to the common component is smaller than the corresponding standard deviation for the responses to sector-specific shocks; v) the cross-sectional mean of the correlations between the sector-specific component of PCE inflation rates and the corresponding sector-specific component of the growth rate in quantities is negative - the same applies to the fluctuations that are driven by the common component.

A major improvement in quantitative performance relative to the simply parameterized model studied previously is the much lower correlation between the speed of price responses to common and specific shocks produced by the estimated model. The model with identically-parameterized sectoral shocks produces an extremely high correlation between those speeds of price responses, due to their tight link with the sectoral frequencies of price changes. Heterogeneity in the estimated shock dynamics breaks that tight link and helps the estimated model get closer to the data. This result underscores the importance of accounting for heterogeneity in the dynamics of the shocks. 
Regarding the cross-section of correlations between components of inflation and growth rates of consumption, a comparison of Tables 2 and 4 with Table 9 reveals that the estimated model captures the main qualitative features of the two distributions, although it misses more nuanced features such as the tails. Importantly, the estimated model produces (on average) a negative correlation between the sector-specific component of inflation rates and the corresponding sector-specific component of the growth rate of quantities, and also between the component of inflation rates and growth rate of quantities that are driven by the common component. This is consistent with supply-type shocks driving most of the variation in these series. ${ }^{28}$

\section{Conclusion}

We construct a relatively simple variant of the New Keynesian model that can endogenously deliver differential responses of sectoral prices to aggregate and sectoral shocks. In particular, contrary to what intuition suggests at a first pass, the model is able to produce faster response of sectoral prices to sector-specific shocks than to aggregate shocks. In fact, getting the model to produce the same response of prices to aggregate and sectoral shocks proves to be somewhat difficult, in that it requires a parameterization of our model that is quite restrictive and arguably unrealistic.

We illustrate the economic mechanisms behind the endogenous differential response of prices to different shocks, and make a quantitative assessment of the model's ability to match facts about sectoral prices established by the recent empirical literature. Despite the fact that the model is highly stylized, we find the results to be surprisingly close to the data.

A model in which price setters allocate limited information-processing capacity to track aggregate and sectoral conditions is also able to rationalize the empirical finding of differential speeds of responses of prices to different shocks (Maćkowiak and Wiederholt 2008, and Maćkowiak et al. 2009). The reason is that sectoral shocks tend to be more volatile, and thus take up most of firms' informationprocessing capacity. This leads them to react quickly to those shocks, at the expense of reacting slowly to aggregate shocks.

A distinctive feature of the aforementional models with limited information-processing capacity is that prices change continuously. This contrasts with the available microeconomic evidence of infrequent price changes. While extending those models to produce nominal price rigidity is certainly feasible, it is not clear whether this would preserve their ability to produce faster responses of prices to sectoral shocks relative to aggregate shocks, absent other endogenous mechanisms such as the ones we uncover in this paper. In our view this remains an important open question for the literature on price setting with limited information-processing capacity.

Finally, the sectoral price facts that we focus on in this paper are still being debated, and are not without credible critics (e.g. Beck et al. 2010, Andrade and Zachariadis 2011, and De Graeve and Walentin 2011). More work is needed to advance our knowledge about this issue, and to clarify points in which different papers seem to produce conflicting findings. Due to the important role of price

\footnotetext{
${ }^{28}$ To justify this interpretation we analyzed different model parameterizations in which we varied the relative variance of demand- and supply-type shocks, and verified that larger supply-type shocks produce more negative price-quantity correlations.
} 
setting in macroeconomic models that are currently used for policy analysis, it will be important to confront those models with whatever new empirical evidence comes about regarding the behavior of disaggregated prices. 


\section{References}

[1] Altissimo, F., B. Mojon, and P. Zaffaroni (2009), "Can Aggregation Explain the Persistence of Inflation?", Journal of Monetary Economics 56: 231-241.

[2] Andrade, P. and M. Zachariadis (2011), "Global Versus Local Shocks in Micro Price Dynamics," mimeo.

[3] Balke, N. and M. Wynne (2007), "The Relative Price Effects of Monetary Shocks," Journal of Macroeconomics 29: 19-36.

[4] Ball, L. and D. Romer (1990), "Real Rigidities and the Non-Neutrality of Money," Review of Economic Studies 57: 183-203.

[5] Basu, S. (1995), "Intermediate Goods and Business Cycles: Implications for Productivity and Welfare," American Economic Review 85: 512-31.

[6] Beck, G., K. Hubrich, and M. Marcellino, (2010), "On the Importance of Sectoral Shocks for Price-setting," mimeo available at http://www.nber.org/ confer/2010/SI2010/efwwprg.html.

[7] Bils, M. and P. Klenow (2004), "Some Evidence on the Importance of Sticky Prices," Journal of Political Economy 112: 947-985.

[8] Boivin, J., M. Giannoni, and I. Mihov (2009), "Sticky prices and monetary policy: evidence from disaggregated U.S. data," American Economic Review 99: 350-384.

[9] Bouakez, H., E. Cardia and F. Ruge-Murcia (2009), "The Transmission of Monetary Policy in a Multi-Sector Economy," International Economic Review 50: 1243-1266.

[10] Burstein A., and C. Hellwig (2007), "Prices and Market Shares in a Menu Cost Model," mimeo available at http://www.econ.ucla.edu/arielb/menucost.pdf.

[11] Calvo, G. (1983), "Staggered Prices in a Utility Maximizing Framework," Journal of Monetary Economics 12: 383-98.

[12] Carlstrom, C., T. Fuerst, F. Ghironi and K. Hernandez (2006b), "Relative Price Dynamics and the Aggregate Economy," mimeo available at http://copland.udel.edu/ kolver/research/index.html.

[13] Carvalho, C. (2006), "Heterogeneity in Price Stickiness and the Real Effects of Monetary Shocks," The B.E. Journal of Macroeconomics (Frontiers) Vol. 2, Iss. 1.

[14] Carvalho, C. and F. Schwartzman (2008), "Heterogeneous Price Setting Behavior and Aggregate Dynamics: Some General Results," mimeo available at http://www.newyorkfed.org/research/economists/carvalho/papers.html.

[15] Clark, T. (2006), "Disaggregate Evidence on the Persistence of Consumer Price Inłation," Journal of Applied Econometrics 21: 563-587. 
[16] De Graeve, F. and K. Walentin (2011), "Stylized (Arte)Facts on Sectoral Inflation," mimeo.

[17] Gelman, A., J. Carlin, H. Stern and D. Rubin (2003), Bayesian Data Analysis, 2nd edition, Chapman \& Hall/CRC.

[18] Gertler, M. and J. Leahy (2008), "A Phillips Curve with an Ss Foundation," Journal of Political Economy 116: 533-572.

[19] Kimball, M. (1995), "The Quantitative Analytics of the Basic Neomonetarist Model," Journal of Money, Credit and Banking 27: 1241-1277.

[20] Lee, J. W. (2007), "Heterogeneous Households, Real Rigidity, and Estimated Duration of Price Contract in a Sticky-Price DSGE Model," mimeo available at http://econweb.rutgers.edu/jwlee/.

[21] Maćkowiak, B., E. Moench, and M. Wiederholt (2009), "Sectoral Price Data and Models of Price Setting," Journal of Monetary Economics 56: 78-99.

[22] Nakamura, E. and J. Steinsson (2008), "Five Facts About Prices: A Reevaluation of Menu Cost Models," Quarterly Journal of Economics 123: 1415-1464.

[23] _ (2010), "Monetary Non-Neutrality in a Multi-Sector Menu Cost Model," forthcoming in the Quarterly Journal of Economics.

[24] Reis, R. and M. Watson (2010), “|Relative Goods' Prices, Pure Inflation and the Phillips Correlation," American Economic Journal: Macroeconomics 2: 128-157.

[25] Shamloo, M. (2010), "Price-Setting in a Model with Production Chain: Evidence from Microdata," IMF Working Paper No. 10/82.

[26] Woodford, M. (2003), Interest and Prices: Foundations of a Theory of Monetary Policy, Princeton University Press. 


\section{A The mechanism: the role of each ingredient}

Table 10 reports the results for the first-pass specification. After that, Tables 11-15 present the results for specifications that deviate from the first-pass one by "activating" the three ingredients of our model. Table 11 considers only the Taylor rule, Table 12 considers only input-output linkages, and Table 13 considers only labor segmentation. After that, Tables 14 and 15 consider specifications that combine the Taylor rule with, respectively, input-output linkages, and labor segmentation. The values for the model parameters are the ones described in Subsection 5.1, and the results are based on theoretical impulse responses to the aggregate and sectoral productivity shocks.

Table 10: Speed of response to productivity shocks - first-pass specification

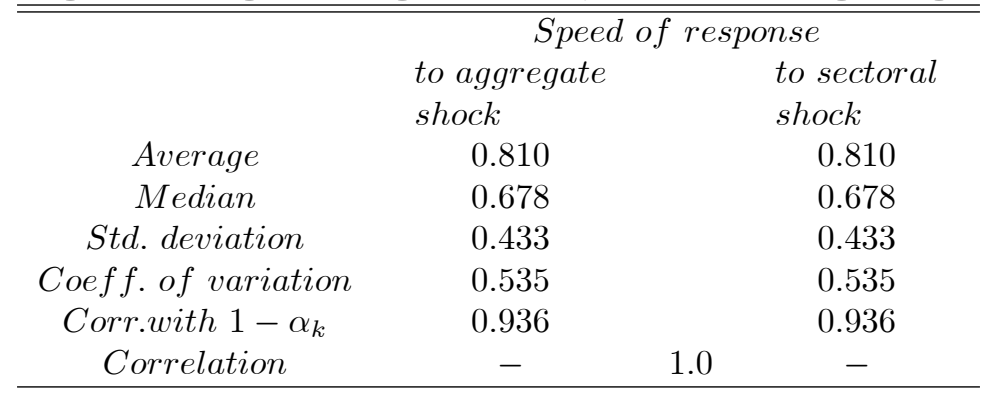

Table 11: Speed of response to productivity shocks - Taylor rule only

\begin{tabular}{|c|c|c|c|}
\hline & \multicolumn{3}{|c|}{ Speed of response } \\
\hline & $\begin{array}{l}\text { to aggregate } \\
\text { shock }\end{array}$ & & $\begin{array}{l}\text { to sectoral } \\
\text { shock }\end{array}$ \\
\hline Average & 0.263 & & 0.768 \\
\hline Median & 0.252 & & 0.653 \\
\hline Std. deviation & 0.060 & & 0.403 \\
\hline Coeff. of variation & 0.228 & & 0.525 \\
\hline Corr.with $1-\alpha_{k}$ & 0.890 & & 0.929 \\
\hline Correlation & - & 0.984 & - \\
\hline
\end{tabular}

Table 12: Speed of response to productivity shocks - input-output only

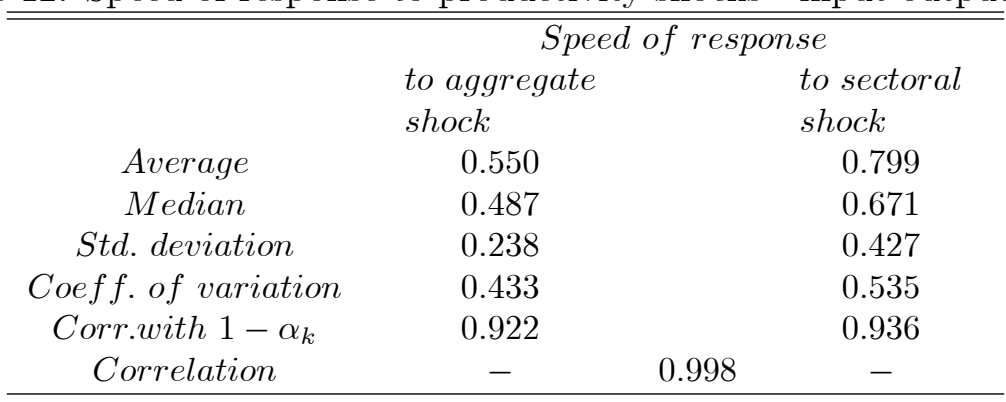


Table 13: Speed of response to productivity shocks - labor segmentation only

\begin{tabular}{|c|c|c|c|}
\hline & \multicolumn{3}{|c|}{ Speed of response } \\
\hline & $\begin{array}{l}\text { to aggregate } \\
\text { shock }\end{array}$ & & $\begin{array}{l}\text { to sectoral } \\
\text { shock }\end{array}$ \\
\hline Average & 0.989 & & 1.184 \\
\hline Median & 0.993 & & 1.181 \\
\hline Std. deviation & 0.348 & & 0.454 \\
\hline Coeff. of variation & 0.352 & & 0.383 \\
\hline Corr.with $1-\alpha_{k}$ & 0.799 & & 0.807 \\
\hline Correlation & - & 0.999 & - \\
\hline
\end{tabular}

Table 14: Speed of response to productivity shocks - Taylor rule and input-output linkages

\begin{tabular}{|c|c|c|c|}
\hline & \multicolumn{3}{|c|}{ Speed of response } \\
\hline & $\begin{array}{l}\text { to aggregate } \\
\text { shock }\end{array}$ & & $\begin{array}{l}\text { to sectoral } \\
\text { shock }\end{array}$ \\
\hline Average & 0.287 & & 0.757 \\
\hline Median & 0.272 & & 0.645 \\
\hline Std. deviation & 0.077 & & 0.400 \\
\hline Coeff. of variation & 0.266 & & 0.529 \\
\hline Corr.with $1-\alpha_{k}$ & 0.900 & & 0.925 \\
\hline Correlation & - & 0.985 & - \\
\hline
\end{tabular}

Table 15: Speed of response to productivity shocks - Taylor rule and labor segmentation

\begin{tabular}{|c|c|c|c|}
\hline & \multicolumn{3}{|c|}{ Speed of response } \\
\hline & $\begin{array}{l}\text { to aggregate } \\
\text { shock }\end{array}$ & & $\begin{array}{l}\text { to sectoral } \\
\text { shock }\end{array}$ \\
\hline Average & 0.238 & & 1.085 \\
\hline Median & 0.242 & & 1.092 \\
\hline Std. deviation & 0.026 & & 0.417 \\
\hline Coeff. of variation & 0.109 & & 0.385 \\
\hline Corr.with $1-\alpha_{k}$ & 0.742 & & 0.770 \\
\hline Correlation & - & 0.960 & - \\
\hline
\end{tabular}




\section{B Details of the estimation algorithm}

Our specific estimation strategy is as follows. We run two numerical optimization routines sequentially in order to maximize the posterior distribution. This determines the starting point of the Markov chain and provides a first crude estimate of the covariance matrix for our Random-Walk Metropolis Gaussian jumping distribution. The first optimization routine is csminwel by Chris Sims, while the second is fminsearch from Matlab's optimization toolbox. Following the first optimization, we run additional rounds, starting from initial values obtained by perturbing the original initial values, and then the estimate of the first optimization round.

Before running the Markov chains we transform all parameters to have full support on the real line. Then we run a so-called adaptive phase of the Markov chain, with three sub-phases of 100, 200, and 600 thousand iterations, respectively. At the end of each sub-phase we discard the first half of the draws, update the estimate of the posterior mode, and compute a sample covariance matrix to be used in the jumping distribution in the next sub-phase. Finally, in each sub-phase we rescale the covariance matrix inherited from the previous sub-phase in order to get a fine-tuned covariance matrix that yields rejection rates as close as possible to $0.77 .{ }^{29}$ Next we run the so-called fixed phase of the MCMC. We take the estimate of the posterior mode and sample covariance matrix from the adaptive phase, and run 5 parallel chains of 300,000 iterations each. Again, before making the draws that will form the sample we rescale such covariance matrix in order to get rejection rates as close as possible to 0.77 . To initialize each chain we draw from a candidate normal distribution centered on the posterior mode estimate, with covariance matrix given by 9 times the fine-tuned covariance matrix. We check for convergence for the latter $2 / 3 \mathrm{~s}$ of the draws of all 5 chains by calculating the potential scale reduction ${ }^{30}$ (PSR) factors for each parameter and inspecting the histograms of all marginal distributions across the parallel chains. Upon convergence, the latter $2 / 3$ s of the draws of all 5 chains are combined to form a posterior sample of 1 million draws.

\footnotetext{
${ }^{29}$ This is the optimal rejection rate under certain conditions. See Gelman et al. (2003, p. 306).

${ }^{30}$ For each parameter, the PSR factor is the ratio of (square root of) an estimate of the marginal posterior variance to the average variance within each chain. This factor expresses the potential reduction in the scaling of the estimated marginal posterior variance relative to the true distribution by increasing the number of iterations in the Markov-chain algorithm. Hence, as the PSR factor approaches unity, it is a sign of convergence of the Markov-chain for the estimated parameter. See Gelman et al. (2003, p. $294 \mathrm{ff}$ ) for more information. For all specifications we require that the factor be below 1.01 for all parameters.
} 


\section{About the estimated model}

Table 16: Sectors and weights, 15-sector model

\begin{tabular}{llccc}
\hline \hline$k$ & Categories & Weights $\left(n_{k}\right)$ in $\%$ & $\alpha_{k}^{1)}$ & $\begin{array}{c}\text { Duration }^{2)} \\
\text { in months }\end{array}$ \\
\hline 1 & Motor vehicles and Parts & 4.56 & 0.596 & 2.48 \\
2 & Furnishings and durable household equipment & 2.41 & 0.785 & 4.64 \\
3 & Recreational goods and vehicles & 1.82 & 0.826 & 5.75 \\
4 & Other durable goods & 1.27 & 0.82 & 5.55 \\
5 & Food and beverages purchased for off-premises consumption & 8.97 & 0.689 & 3.21 \\
6 & Clothing and footwear & 3.32 & 0.692 & 3.25 \\
7 & Gasoline and other energy goods & 4.19 & 0.148 & 1.17 \\
8 & Other nondurable goods & 7.48 & 0.815 & 5.41 \\
9 & Housing and utilities & 19.59 & 0.596 & 2.48 \\
10 & Health care & 15.65 & 0.95 & 20.00 \\
11 & Transportation services & 3.35 & 0.721 & 3.59 \\
12 & Recreation services & 3.68 & 0.899 & 9.90 \\
13 & Food services and Accommodations & 6.65 & 0.843 & 6.36 \\
14 & Financial services and insurance & 8.10 & 0.921 & 12.60 \\
15 & Other services & 8.97 & 0.864 & 7.35 \\
\hline
\end{tabular}

1) monthly "infrequency" of price changes. 2) expected duration of price spells: $\left(1-\alpha_{k}\right)^{-1}$.

Table 17: Priors and posteriors - Taylor rule and aggregate shocks, 15-sector model

\begin{tabular}{cccccccc}
\hline \hline & & & & & & & \\
& Prior & Prior Mean (Std) & Posterior Mode & Posterior Mean & {$[5 \%$} & Median & $95 \%]$ \\
\hline$\phi_{y}$ & $\mathrm{~N}$ & $0.5 / 12(0.05)$ & $6 \times 10^{-16}$ & $4 \times 10^{-14}$ & 0.0000 & 0.0000 & 0.0030 \\
$\phi_{\pi}$ & $\mathrm{N}$ & $1.5(0.25)$ & 1.0334 & 1.0275 & 1.0204 & 1.0270 & 1.0362 \\
$\rho_{\mu}$ & $\mathrm{B}$ & $0.7(0.1)$ & 0.3545 & 0.3755 & 0.3276 & 0.3764 & 0.4202 \\
$\rho_{\gamma}$ & $\mathrm{B}$ & $0.7(0.1)$ & 0.9941 & 0.9948 & 0.9880 & 0.9898 & 0.9919 \\
$\rho_{a}$ & $\mathrm{~B}$ & $0.7(0.1)$ & 0.9939 & 0.9899 & 0.9913 & 0.9950 & 0.9974 \\
$\sigma_{\mu}$ & $\mathrm{IG}$ & $0.00125(0.00125)$ & 0.0022 & 0.0022 & 0.0021 & 0.0022 & 0.0024 \\
$\sigma_{\gamma}$ & $\mathrm{IG}$ & $0.005(0.005)$ & 0.0095 & 0.0094 & 0.0058 & 0.0087 & 0.0152 \\
$\sigma_{a}$ & $\mathrm{IG}$ & $0.005(0.005)$ & 0.0031 & 0.0033 & 0.0030 & 0.0033 & 0.0037 \\
\hline
\end{tabular}


Table 18: Priors and posteriors - sectoral productivity shocks, 15-sector model

\begin{tabular}{|c|c|c|c|c|c|c|c|}
\hline & Prior & Prior Mean (Std) & Posterior Mode & Posterior Mean & {$[5 \%$} & Median & $95 \%]$ \\
\hline$\rho_{A_{1}}$ & $\mathrm{~B}$ & $0.7(0.1)$ & 0.9165 & 0.9297 & 0.9081 & 0.9300 & 0.9505 \\
\hline$\rho_{A_{2}}$ & B & $0.7(0.1)$ & 0.8270 & 0.8206 & 0.7724 & 0.8213 & 0.8663 \\
\hline$\rho_{A_{3}}$ & B & $0.7(0.1)$ & 0.9262 & 0.9283 & 0.9030 & 0.9285 & 0.9532 \\
\hline $\begin{array}{l}\rho_{A_{3}} \\
\rho_{A_{4}}\end{array}$ & B & $0.7(0.1)$ & 0.7433 & 0.7830 & 0.7270 & 0.7832 & 0.8384 \\
\hline$\rho_{A_{5}}$ & B & $0.7(0.1)$ & 0.8060 & 0.7464 & 0.6916 & 0.7467 & 0.7999 \\
\hline$\rho_{A_{6}}$ & B & $0.7(0.1)$ & 0.8099 & 0.8176 & 0.7679 & 0.8178 & 0.8664 \\
\hline$\rho_{A_{7}}$ & B & $0.7(0.1)$ & 0.9453 & 0.9436 & 0.9300 & 0.9438 & 0.9563 \\
\hline$\rho_{A_{8}}$ & B & $0.7(0.1)$ & 0.8728 & 0.8270 & 0.7818 & 0.8281 & 0.8689 \\
\hline$\rho_{A_{9}}$ & B & $0.7(0.1)$ & 0.9146 & 0.9013 & 0.8775 & 0.9018 & 0.9235 \\
\hline$\rho_{A_{10}}$ & B & $0.7(0.1)$ & 0.9418 & 0.9411 & 0.9342 & 0.9412 & 0.9475 \\
\hline$\rho_{A_{11}}$ & B & $0.7(0.1)$ & 0.6401 & 0.6308 & 0.5545 & 0.6307 & 0.7072 \\
\hline$\rho_{A_{12}}$ & B & $0.7(0.1)$ & 0.7625 & 0.7836 & 0.7440 & 0.7840 & 0.8218 \\
\hline$\rho_{A_{13}}$ & B & $0.7(0.1)$ & 0.7286 & 0.7702 & 0.7253 & 0.7707 & 0.8131 \\
\hline$\rho_{A_{14}}$ & B & $0.7(0.1)$ & 0.9591 & 0.9567 & 0.9520 & 0.9568 & 0.9612 \\
\hline \multirow[t]{2}{*}{$\rho_{A_{15}}$} & $\mathrm{~B}$ & $0.7(0.1)$ & 0.8293 & 0.8078 & 0.7710 & 0.8085 & 0.8426 \\
\hline & Prior & Prior Mean (Std) & Posterior Mode & Posterior Mean & {$[5 \%$} & Median & $95 \%]$ \\
\hline$\sigma_{A_{1}}$ & IG & $0.05(0.02)$ & 0.0130 & 0.0127 & 0.0118 & 0.0127 & 0.0137 \\
\hline$\sigma_{A_{2}}$ & IG & $0.05(0.02)$ & 0.0327 & 0.0336 & 0.0301 & 0.0335 & 0.0374 \\
\hline$\sigma_{A_{3}}$ & IG & $0.05(0.02)$ & 0.0321 & 0.0301 & 0.0272 & 0.0300 & 0.0333 \\
\hline$\sigma_{A_{4}}$ & IG & $0.05(0.02)$ & 0.0981 & 0.0880 & 0.0776 & 0.0878 & 0.0990 \\
\hline$\sigma_{A_{5}}$ & IG & $0.05(0.02)$ & 0.0132 & 0.0145 & 0.0132 & 0.0144 & 0.0159 \\
\hline$\sigma_{A_{6}}$ & IG & $0.05(0.02)$ & 0.0250 & 0.0241 & 0.0220 & 0.0240 & 0.0264 \\
\hline$\sigma_{A_{7}}$ & IG & $0.05(0.02)$ & 0.0393 & 0.0411 & 0.0384 & 0.0411 & 0.0441 \\
\hline$\sigma_{A_{8}}$ & IG & $0.05(0.02)$ & 0.0280 & 0.0319 & 0.0287 & 0.0318 & 0.0355 \\
\hline$\sigma_{A_{9}}$ & IG & $0.05(0.02)$ & 0.0057 & 0.0059 & 0.0055 & 0.0059 & 0.0064 \\
\hline$\sigma_{A_{10}}$ & IG & $0.05(0.02)$ & 0.0506 & 0.0540 & 0.0503 & 0.0539 & 0.0580 \\
\hline$\sigma_{A_{11}}$ & IG & $0.05(0.02)$ & 0.0371 & 0.0363 & 0.0328 & 0.0363 & 0.0401 \\
\hline$\sigma_{A_{12}}$ & IG & $0.05(0.02)$ & 0.0669 & 0.0664 & 0.0587 & 0.0661 & 0.0748 \\
\hline$\sigma_{A_{13}}$ & IG & $0.05(0.02)$ & 0.0283 & 0.0262 & 0.0232 & 0.0261 & 0.0295 \\
\hline$\sigma_{A_{14}}^{A_{13}}$ & IG & $0.05(0.02)$ & 0.1591 & 0.1607 & 0.1494 & 0.1604 & 0.1727 \\
\hline$\sigma_{A_{15}}$ & IG & $0.05(0.02)$ & 0.0289 & 0.0325 & 0.0292 & 0.0324 & 0.0361 \\
\hline
\end{tabular}


Table 19: Priors and posteriors - sectoral demand shocks, 15-sector model

\begin{tabular}{|c|c|c|c|c|c|c|c|}
\hline & Prior & Prior Mean (Std) & Posterior Mode & Posterior Mean & {$[5 \%$} & Median & $95 \%]$ \\
\hline$\rho_{D_{1}}$ & B & $0.7(0.1)$ & 0.8147 & 0.7869 & 0.7417 & 0.7875 & 0.8300 \\
\hline$\rho_{D_{2}}$ & B & $0.7(0.1)$ & 0.9872 & 0.9790 & 0.9672 & 0.9795 & 0.9889 \\
\hline$\rho_{D_{3}}$ & B & $0.7(0.1)$ & 0.9551 & 0.9769 & 0.9620 & 0.9776 & 0.9894 \\
\hline$\rho_{D_{4}}$ & B & $0.7(0.1)$ & 0.9884 & 0.9791 & 0.9671 & 0.9795 & 0.9893 \\
\hline$\rho_{D_{5}}$ & B & $0.7(0.1)$ & 0.9795 & 0.9848 & 0.9769 & 0.9851 & 0.9919 \\
\hline$\rho_{D_{6}}$ & B & $0.7(0.1)$ & 0.9182 & 0.9379 & 0.9047 & 0.9395 & 0.9660 \\
\hline$\rho_{D_{7}}$ & B & $0.7(0.1)$ & 0.9651 & 0.9736 & 0.9606 & 0.9740 & 0.9855 \\
\hline$\rho_{D_{8}}$ & B & $0.7(0.1)$ & 0.9545 & 0.9514 & 0.9262 & 0.9530 & 0.9714 \\
\hline$\rho_{D_{9}}$ & B & $0.7(0.1)$ & 0.9820 & 0.9709 & 0.9544 & 0.9717 & 0.9845 \\
\hline$\rho_{D_{10}}$ & B & $0.7(0.1)$ & 0.9940 & 0.9898 & 0.9837 & 0.9901 & 0.9951 \\
\hline$\rho_{D_{11}}$ & B & $0.7(0.1)$ & 0.9791 & 0.9725 & 0.9547 & 0.9734 & 0.9872 \\
\hline$\rho_{D_{12}}$ & $\mathrm{~B}$ & $0.7(0.1)$ & 0.9025 & 0.9177 & 0.8389 & 0.9257 & 0.9677 \\
\hline$\rho_{D_{13}}$ & B & $0.7(0.1)$ & 0.9817 & 0.9739 & 0.9607 & 0.9745 & 0.9851 \\
\hline$\rho_{D_{14}}$ & B & $0.7(0.1)$ & 0.9622 & 0.9343 & 0.9036 & 0.9349 & 0.9628 \\
\hline$\rho_{D_{15}}$ & $\mathrm{~B}$ & $0.7(0.1)$ & 0.9842 & 0.9766 & 0.9646 & 0.9771 & 0.9873 \\
\hline & Prior & Prior Mean (Std) & Posterior Mode & Posterior Mean & {$[5 \%$} & Median & $95 \%]$ \\
\hline$\sigma_{D_{1}}$ & IG & $0.05(0.02)$ & 0.0565 & 0.0594 & 0.0555 & 0.0593 & 0.0637 \\
\hline$\sigma_{D_{2}}$ & $\mathrm{IG}$ & $0.05(0.02)$ & 0.0104 & 0.0100 & 0.0093 & 0.0100 & 0.0107 \\
\hline$\sigma_{D_{3}}$ & $\mathrm{IG}$ & $0.05(0.02)$ & 0.0146 & 0.0138 & 0.0128 & 0.0138 & 0.0148 \\
\hline$\sigma_{D_{4}}$ & $\mathrm{IG}$ & $0.05(0.02)$ & 0.0172 & 0.0158 & 0.0148 & 0.0158 & 0.0170 \\
\hline$\sigma_{D_{5}}$ & IG & $0.05(0.02)$ & 0.0075 & 0.0081 & 0.0075 & 0.0081 & 0.0087 \\
\hline$\sigma_{D_{6}}$ & IG & $0.05(0.02)$ & 0.0127 & 0.0129 & 0.0120 & 0.0128 & 0.0138 \\
\hline$\sigma_{D_{7}}$ & IG & $0.05(0.02)$ & 0.0854 & 0.0868 & 0.0812 & 0.0867 & 0.0928 \\
\hline$\sigma_{D_{8}}$ & IG & $0.05(0.02)$ & 0.0071 & 0.0077 & 0.0071 & 0.0076 & 0.0083 \\
\hline$\sigma_{D_{9}}$ & IG & $0.05(0.02)$ & 0.0103 & 0.0104 & 0.0097 & 0.0104 & 0.0113 \\
\hline$\sigma_{D_{10}}$ & IG & $0.05(0.02)$ & 0.0062 & 0.0064 & 0.0059 & 0.0064 & 0.0070 \\
\hline$\sigma_{D_{11}}$ & IG & $0.05(0.02)$ & 0.0140 & 0.0134 & 0.0124 & 0.0133 & 0.0143 \\
\hline$\sigma_{D_{12}}$ & IG & $0.05(0.02)$ & 0.0077 & 0.0074 & 0.0069 & 0.0074 & 0.0080 \\
\hline$\sigma_{D_{13}}$ & IG & $0.05(0.02)$ & 0.0078 & 0.0086 & 0.0080 & 0.0086 & 0.0093 \\
\hline$\sigma_{D_{14}}$ & IG & $0.05(0.02)$ & 0.0172 & 0.0170 & 0.0158 & 0.0169 & 0.0182 \\
\hline$\sigma_{D_{15}}$ & IG & $0.05(0.02)$ & 0.0089 & 0.0087 & 0.0080 & 0.0087 & 0.0094 \\
\hline
\end{tabular}




\section{C.1 Model-implied IRFs}

Figures 29-30: Estimated-model-implied IRFs - 15 sectors
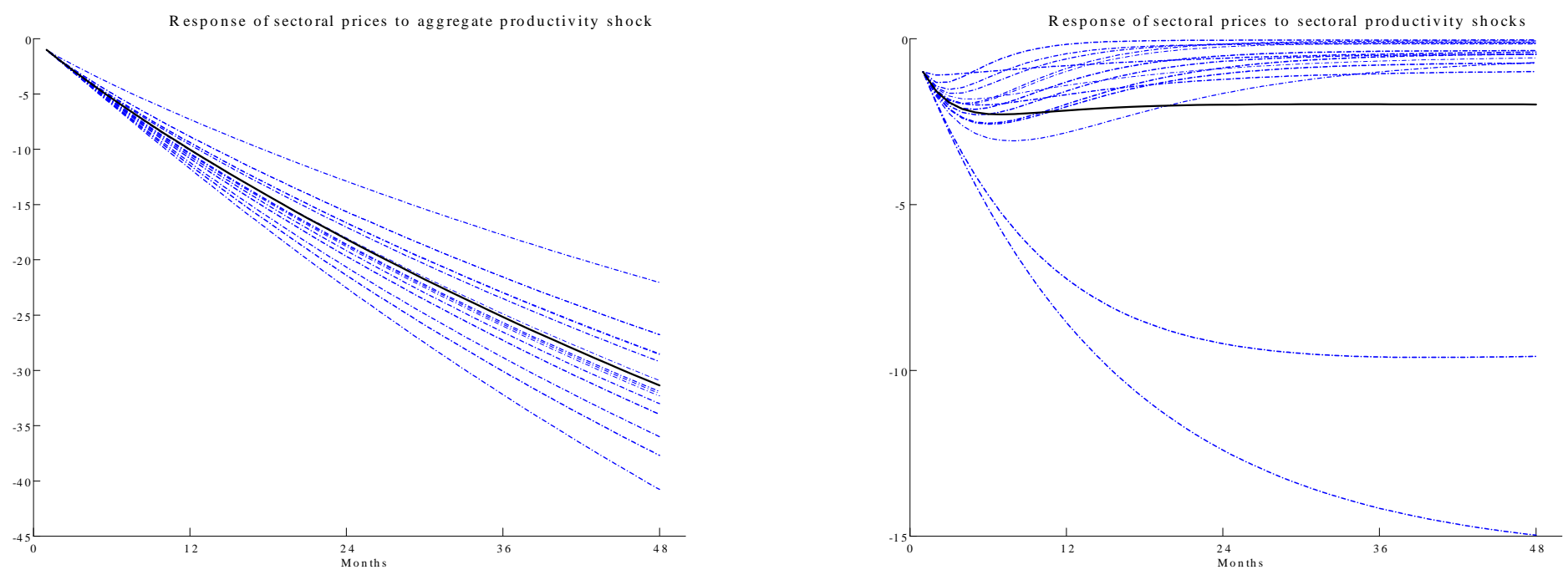

Figures 31-32: Estimated-model-implied IRFs - 15 sectors
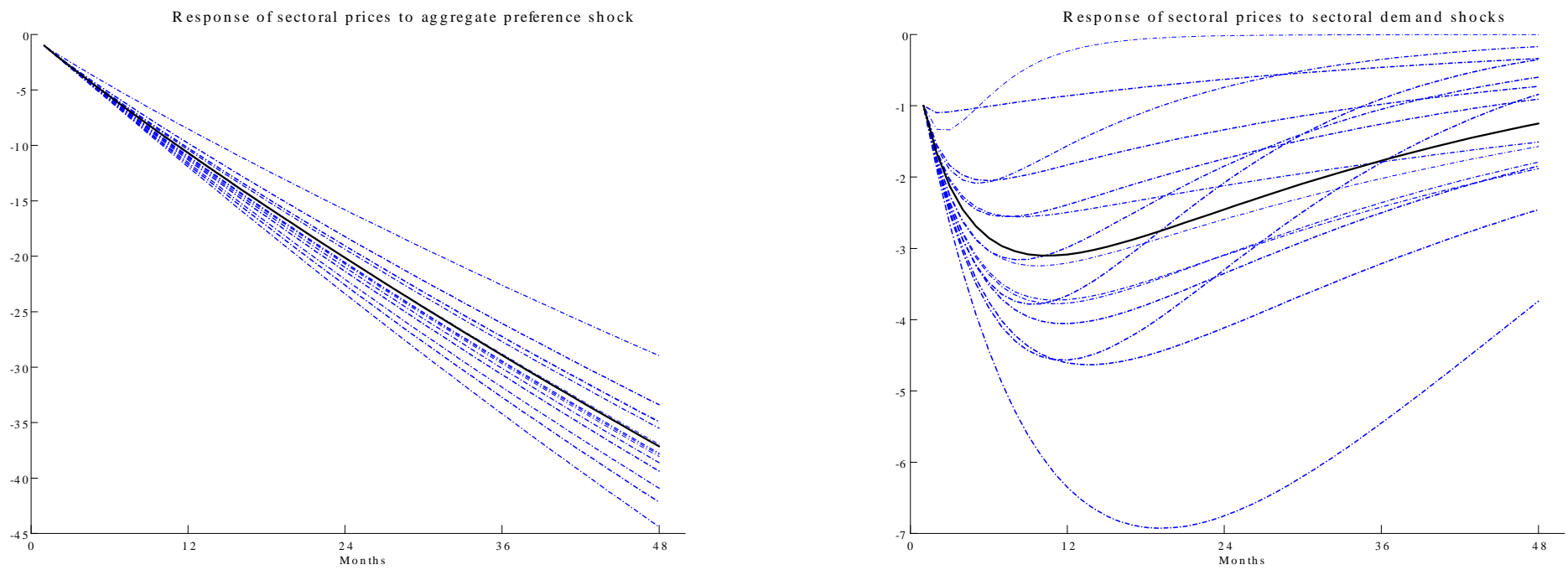

\section{Robustness}

\section{D.1 50-sector FAVAR}

We re-estimate the FAVAR using the nominal interest rate, hours growth, and all sectoral inflation and sectoral consumption growth rates for the 50 sectors in the third-level disaggregation of the PCE data.

Figures 33-34 and Tables 20-21 report the results analogous to those in Figures 1-6 and Tables 1-2. The bottom line is that the results are very similar to those of the 15-sector FAVAR. 
Figures 33-34: Empirical IRFs - FAVAR
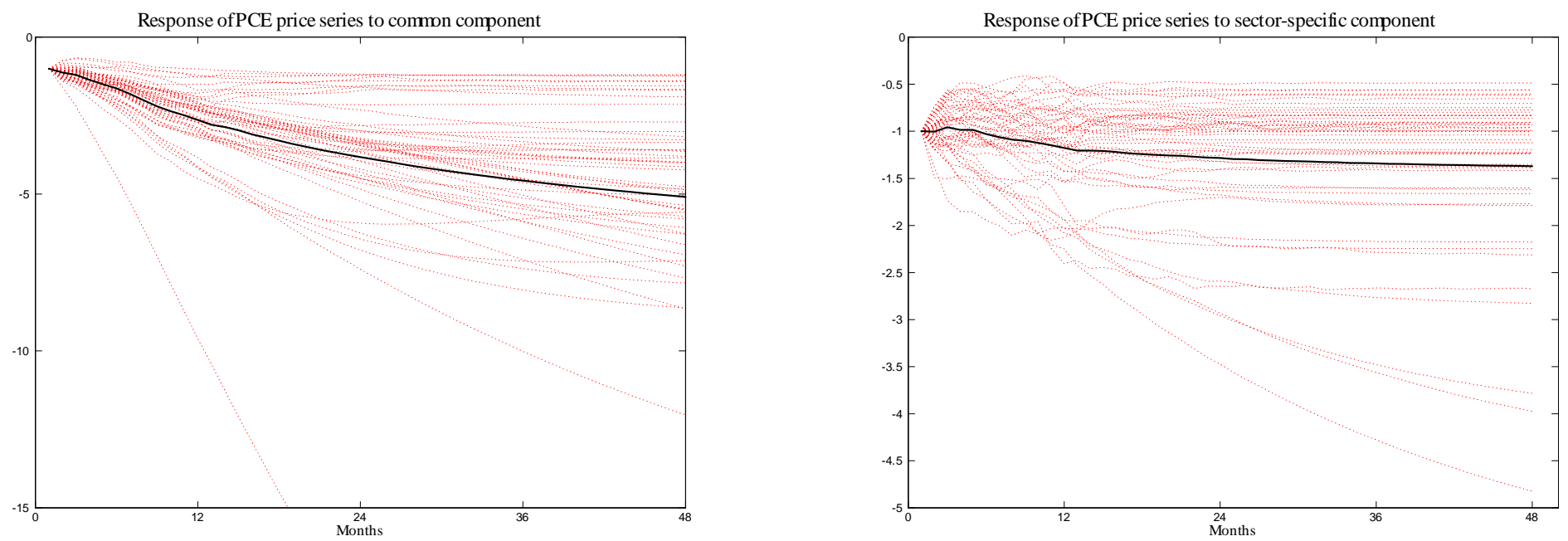

Figures 35-36: Cross-sectional distribution of speed of responses
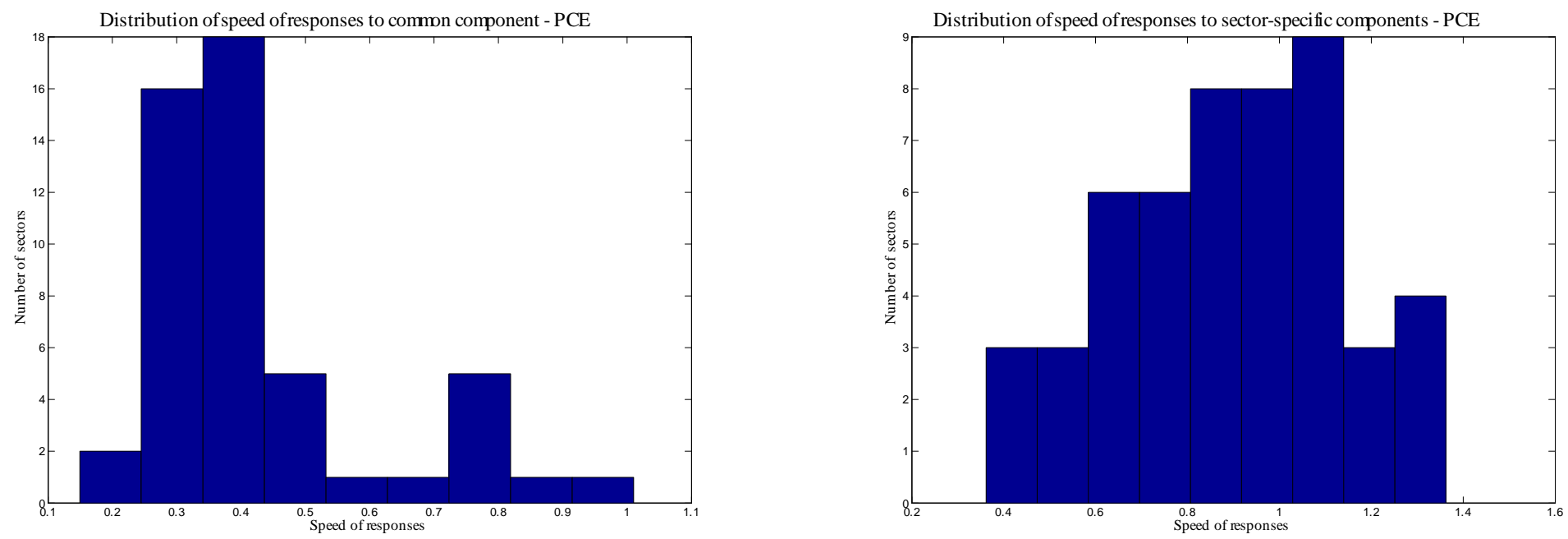

Table 20: Statistics on the speed of responses to shocks - 50-sector FAVAR

\begin{tabular}{|c|c|c|c|}
\hline & \multicolumn{3}{|c|}{ Speed of response } \\
\hline & to common & & to specific \\
\hline & component & & components \\
\hline Average & 0.427 & & 0.891 \\
\hline Median & 0.370 & & 0.912 \\
\hline Std. deviation & 0.184 & & 0.249 \\
\hline Coeff. of variation & 0.431 & & 0.280 \\
\hline Corr.with $1-\alpha_{k}$ & 0.427 & & 0.264 \\
\hline Correlation & - & 0.177 & - \\
\hline
\end{tabular}


Figures 37-38: Cross-section of correlations between components of prices and quantities Correlations of sector-specific components of PCE prices and quantities

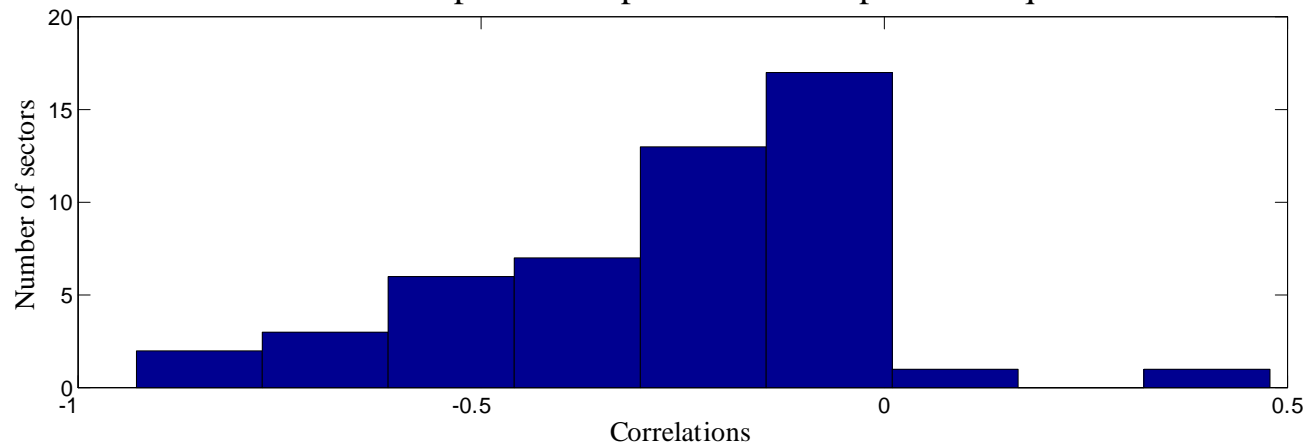

Correlations of common components of PCE prices and quantities

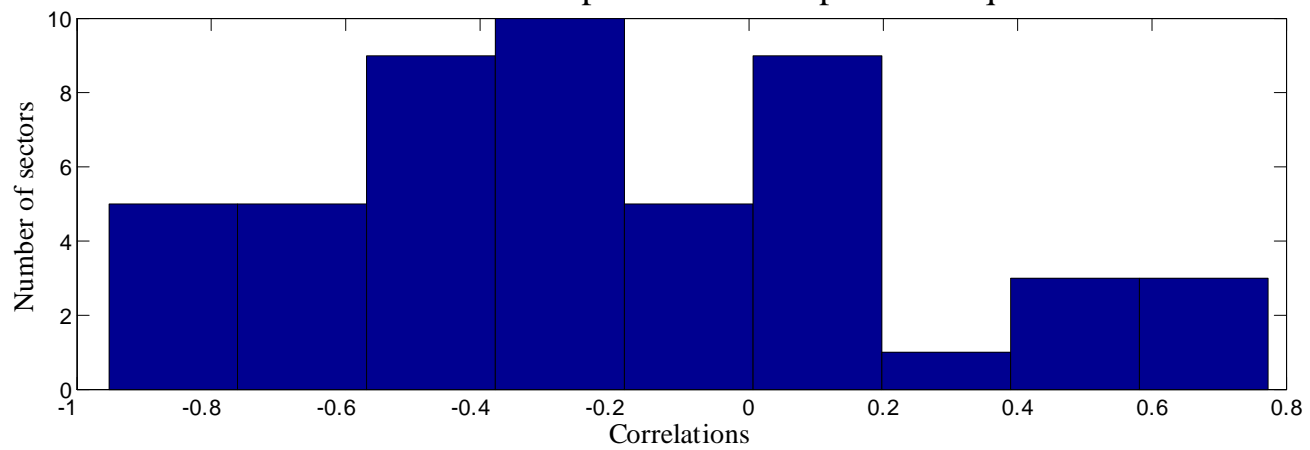

Table 21: Statistics on the correlations between components of prices and quantities - 50-sector FAVAR

\begin{tabular}{|c|c|c|}
\hline & \multicolumn{2}{|c|}{$\begin{array}{l}\text { Correlation between inflation } \\
\text { and growth of quantities }\end{array}$} \\
\hline & $\begin{array}{l}\text { Common } \\
\text { component }\end{array}$ & $\begin{array}{l}\text { Specific } \\
\text { components }\end{array}$ \\
\hline Average & -0.204 & -0.261 \\
\hline Median & -0.252 & -0.186 \\
\hline Max. & 0.773 & 0.478 \\
\hline Min. & -0.952 & -0.927 \\
\hline
\end{tabular}




\section{E Steady state}

As mentioned in the main text, we solve the model by log-linearizing equilibrium conditions around a symmetric non-stochastic zero-inflation steady state, which is detailed here. A non-stochastic steadystate equilibrium is, in fact, not generally symmetric. In particular, it depends on the steady-state levels of sector-specific productivity $\left\{A_{k}\right\}_{k=1}^{K}$, and the sector-specific parameters that measure the

relative disutilities of supplying hours, $\left\{\omega_{k}\right\}_{k=1}^{K}$. For simplicity, we make two assumptions that deliver a symmetric steady state: i) the steady-state levels of sector-specific productivities are the same across sectors: specifically, $A_{k}=1$ for all $k$, without loss of generality; ${ }^{31}$ ii) $\omega_{k}=n_{k}^{-\varphi}$ for all $k$. This last assumption relates the relative disutilies of labor to the size of the sectors, and equalizes steady-state sectoral wages.

We solve for $\left\{Y, C, Z, H, \frac{W}{P}, \frac{\Pi}{P}\right\}$ : the steady state values of aggregate gross output, aggregate value added-output (i.e. GDP), aggregate intermediate input usage, aggregate hours, real wage, and real profits. Once we obtain these aggregate variables, it is trivial to characterize the steady-state values for sectoral and micro variables using the symmetric nature of the steady state (i.e. $Y_{k}=n_{k} Y_{k}(i)=n_{k} Y$, $C_{k}=n_{k} C_{k}(i)=n_{k} C, Z_{k}=n_{k} Z_{k}(i)=n_{k} Z, H_{k}=n_{k} H_{k}(i)=n_{k} H, \Pi_{k}(i)=\Pi, W_{k}=W$, and $\left.\frac{P(i)}{P}=\frac{P_{k}}{P}=1\right)$.

After exploiting the symmetry and market-clearing conditions, the system of equilibrium conditions can be reduced to the following seven equations:

$$
\begin{aligned}
C & =\left(\frac{W}{P}\right) H+\left(\frac{\Pi}{P}\right) \\
\left(\frac{W}{P}\right) & =H^{\varphi} C \\
Y & =H^{1-\delta} Z^{\delta} \\
Y & =C+Z \\
\left(\frac{\Pi}{P}\right) & =Y-\left(\frac{W}{P}\right) H-Z \\
Z & =\frac{\delta}{1-\delta}\left(\frac{W}{P}\right) H \\
1 & =\left(\frac{\theta}{\theta-1}\right) \chi\left(\frac{W}{P}\right)^{1-\delta},
\end{aligned}
$$

where $\chi \equiv \frac{1}{1-\delta}\left(\frac{\delta}{1-\delta}\right)^{-\delta}$.

First, it is trivial to obtain the real wage from (23):

$$
\left(\frac{W}{P}\right)=\left(\frac{1}{\chi} \frac{\theta-1}{\theta}\right)^{\frac{1}{1-\delta}}
$$

\footnotetext{
${ }^{31}$ Similary, we fix the steady-state level of all other exogenous processes at unity.
} 
Next, we substitute out $Z$ in (19) and (21) using (22), which gives:

$$
\begin{aligned}
Y & =H\left(\frac{\delta}{1-\delta}\right)^{\delta}\left(\frac{W}{P}\right)^{\delta} \\
\left(\frac{\Pi}{P}\right) & =Y-\left[\frac{1}{1-\delta}\right]\left(\frac{W}{P}\right) H .
\end{aligned}
$$

Combining the two equations above, we substitute out $H$ and express real profits as a function of the real wage and output:

$$
\left(\frac{\Pi}{P}\right)=\left[1-\chi\left(\frac{W}{P}\right)^{1-\delta}\right] Y .
$$

But, $\chi\left(\frac{W}{P}\right)^{1-\delta}=\frac{\theta-1}{\theta}$ from (23), and consequently we obtain:

$$
\left(\frac{\Pi}{P}\right)=\frac{1}{\theta} Y
$$

Equation (17) indicates that aggregate value-added output should be equal to the sum of labor income and real profits:

$$
\begin{aligned}
C & =\left(\frac{W}{P}\right) H+\left(\frac{\Pi}{P}\right) \\
& =\frac{1-\delta}{\delta} Z+\frac{1}{\theta} Y \\
& =\frac{1-\delta}{\delta}(Y-C)+\frac{1}{\theta} Y \\
& \Longrightarrow C=\left[1-\delta\left(\frac{\theta-1}{\theta}\right)\right] Y .
\end{aligned}
$$

Consequently, aggregate intermediate input usage is obtained as:

$$
\begin{aligned}
Z & =Y-C=Y-\left[1-\delta\left(\frac{\theta-1}{\theta}\right)\right] Y \\
& \Longrightarrow Z=\delta\left(\frac{\theta-1}{\theta}\right) Y .
\end{aligned}
$$

From (22), total labor hours are given by:

$$
\begin{aligned}
H & =\frac{1-\delta}{\delta}\left(\frac{W}{P}\right)^{-1} Z \\
& =\left(\frac{W}{P}\right)^{-1}(1-\delta)\left(\frac{\theta-1}{\theta}\right) Y \\
& =\left(\frac{1}{\chi} \frac{\theta-1}{\theta}\right)^{\frac{-1}{1-\delta}}(1-\delta)\left(\frac{\theta-1}{\theta}\right) Y \\
& =\left[\delta\left(\frac{\theta-1}{\theta}\right)\right]^{-\frac{\delta}{1-\delta}} Y .
\end{aligned}
$$


So far, we have expressed the steady-state values of $\left\{Y, C, Z, H, \frac{\Pi}{P}\right\}$ in terms of $Y$, which can be obtained using (18):

$$
\begin{aligned}
\left(\frac{W}{P}\right) & =H^{\varphi} C \\
& \Longrightarrow\left(\frac{W}{P}\right)=\left[\delta\left(\frac{\theta-1}{\theta}\right)\right]^{-\frac{\delta \varphi}{1-\delta}}\left[1-\delta\left(\frac{\theta-1}{\theta}\right)\right] Y^{1+\varphi} \\
& \Longrightarrow\left(\frac{1}{\chi} \frac{\theta-1}{\theta}\right)^{\frac{1}{1-\delta}}=\left[\delta\left(\frac{\theta-1}{\theta}\right)\right]^{-\frac{\delta \varphi}{1-\delta}}\left[1-\delta\left(\frac{\theta-1}{\theta}\right)\right] Y^{1+\varphi} \\
& \Longrightarrow Y^{1+\varphi}=\left(\frac{1}{\chi}\right)^{\frac{1}{1-\delta}}\left(\frac{\theta-1}{\theta}\right)^{\frac{1}{1-\delta}}\left[\delta\left(\frac{\theta-1}{\theta}\right)\right]^{\frac{\delta \varphi}{1-\delta}}\left[1-\delta\left(\frac{\theta-1}{\theta}\right)\right]^{-1} \\
& \Longrightarrow Y=\left\{\left(\frac{1}{\chi}\right)^{\frac{1}{1-\delta}}\left(\frac{\theta-1}{\theta}\right)^{\frac{1}{1-\delta}}\left[\delta\left(\frac{\theta-1}{\theta}\right)\right]^{\frac{\delta \varphi}{1-\delta}}\left[1-\delta\left(\frac{\theta-1}{\theta}\right)\right]^{-1}\right\}^{\frac{1}{1+\varphi}} .
\end{aligned}
$$

In the special case in which $\delta=0$, the expression for aggregate gross output simplifies to $Y=$ $\left(\frac{\theta-1}{\theta}\right)^{\frac{1}{1+\varphi}}$, which is the standard result in models without intermediate inputs.

\section{F Loglinear approximation}

Here we present full set of log-linearized equations.

\section{F.1 CES Aggregates, market clearing, and definitions}

$$
\begin{array}{rlrl}
p_{t} & =\sum_{k} n_{k} p_{k, t}, & p_{k, t} & =\frac{1}{n_{k}} \int_{\mathcal{I}_{k}} p_{k, t}(i) d i, \\
y_{t} & =\sum_{k} n_{k} y_{k, t}, & y_{k, t} & =\frac{1}{n_{k}} \int_{\mathcal{I}_{k}} y_{k, t}(i) d i \\
c_{t} & =\sum_{k} n_{k} c_{k, t}, & c_{k, t}=\frac{1}{n_{k}} \int_{\mathcal{I}_{k}} c_{k, t}(i) d i \\
z_{k, t}(i) & =\sum_{k^{\prime}} n_{k} z_{k, k^{\prime}, t}(i), & z_{k, k^{\prime}, t}(i)=\frac{1}{n_{k}} \int_{\mathcal{I}_{k^{\prime}}} z_{k, k^{\prime}, t}\left(i, i^{\prime}\right) d i^{\prime}, \\
h_{k, t} & =\frac{1}{n_{k}} \int_{\mathcal{I}_{k}} h_{k, t}(i) d i, & y_{t}=(1-\psi) c_{t}+\psi z_{t}, \text { with } \\
\psi & \equiv \delta\left(\frac{\theta-1}{\theta}\right) \text { and } z_{t} \equiv \sum_{k} \int_{\mathcal{I}_{k}} z_{k, t}(i) d i .
\end{array}
$$




\section{F.2 Demand functions}

$$
\begin{aligned}
y_{k, t}-y_{t} & =-\eta\left(p_{k, t}-p_{t}\right)+d_{k, t}, \\
y_{k, t}(i)-y_{k, t} & =-\theta\left(p_{k, t}(i)-p_{k, t}\right), \\
c_{k, t}-c_{t} & =-\eta\left(p_{k, t}-p_{t}\right)+d_{k, t}, \\
c_{k, t}(i)-c_{k, t} & =-\theta\left(p_{k, t}(i)-p_{k, t}\right), \\
z_{k, k^{\prime}, t}(i)-z_{k, t}(i) & =-\eta\left(p_{k^{\prime}, t}-p_{t}\right)+d_{k^{\prime}, t}, \\
z_{k, k^{\prime}, t}\left(i, i^{\prime}\right)-z_{k, k^{\prime}, t}(i) & =-\theta\left(p_{k^{\prime}, t}(i)-p_{k^{\prime}, t}\right) .
\end{aligned}
$$

\section{F.3 Household's additional FOCs}

Euler equation:

$$
c_{t}=E_{t}\left[c_{t+1}\right]-\left(i_{t}-E_{t} \pi_{t+1}\right)+\left(\gamma_{t}-E_{t} \gamma_{t+1}\right),
$$

Labor supply:

$$
w_{k, t}-p_{t}=\varphi h_{k, t}+c_{t} .
$$

\section{F.4 Firms}

Production function:

$$
y_{k, t}(i)=a_{t}+a_{k, t}+(1-\delta) h_{k, t}(i)+\delta z_{k, t}(i) .
$$

Cost minimization:

$$
w_{k, t}-p_{t}=z_{k, t}(i)-h_{k, t}(i) .
$$

Nominal marginal cost:

$$
m c_{k, t}=(1-\delta)\left(w_{k, t}-p_{t}\right)-a_{k, t}-a_{t}+p_{t} .
$$

Sectoral Phillips curve:

$$
\pi_{k, t}=\beta E_{t} \pi_{k, t+1}+\frac{\left(1-\alpha_{k}\right)\left(1-\alpha_{k} \beta\right)}{\alpha_{k}}\left[\begin{array}{c}
\frac{(1-\delta) \varphi}{1+\delta \varphi} y_{k, t}+\frac{1}{\eta} c_{k, t}+\left(\frac{1-\delta}{1+\delta \varphi}-\frac{1}{\eta}\right) c_{t} \\
-\frac{1+\varphi}{1+\delta \varphi} a_{t}-\frac{1+\varphi}{1+\delta \varphi} a_{k, t}-\frac{1}{\eta}\left(d_{k, t}-\bar{d}_{t}\right)
\end{array}\right] .
$$

